\title{
Modeling Approaches in Educational Research
}

\author{
Dissertation
}

zur Erlangung des wirtschaftswissenschaftlichen Doktorgrades der Wirtschaftswissenschaftlichen Fakultät der Universität Göttingen

vorgelegt von

Tim Ehlers

aus Göttingen

Göttingen, 2016 
Erstgutachter: Prof. Dr. Robert Schwager

Zweitgutachter: Prof. Dr. Gerhard Rübel

Drittprüfer: Prof. Dr. Olaf Korn

Tag der mündlichen Prüfung: 23. Januar 2017 


\section{Danksagung}

Mein größter Dank gilt meinem Doktorvater Prof. Dr. Robert Schwager für seine hervorragende Betreuung, seine Geduld und die viele Zeit, die er für mich aufgebracht hat. Sein persönliches Engagement an der Universität hat auch meine Arbeit sehr erleichtert. Trotz seiner vielen Verpflichtungen war er bereit mit mir zusammen zwei der Papiere zu schreiben. Dabei hat er mich in den vielen wissenschaftlichen Gesprächen und Diskussionen substanziell gefördert.

Außerdem möchte ich mich herzlich bei meinem Zweitgutachter Prof. Dr. Gerhard Rübel bedanken für die Zeit, die er für das Lesen der Arbeit, das Erstellen des Gutachtens und für das nette Vorgespräch aufgebracht hat.

Desweiteren möchte ich herzlich Prof. Dr. Olaf Korn danken für seine Bereitschaft Mitglied in der Prüfungskommission zu sein. Das freundliche Vorgespräch und seine sympathische Art hat mir im Vorfeld der Disputation sehr geholfen.

Weiterer Dank gilt den Korrektoren meiner Einleitung: Christian Boehme, Christina Handschuch und Maximilian Riedl.

Ich möchte meinem Vater Prof. Dr. Wilfried Ehlers danken für das kritische Korrekturlesen meiner Dissertation. Ihm widme ich in memoriam diese Arbeit. 


\section{Contents}

List of Figures 3

1 Introduction

2 University Graduation and its Dependency on Family Wealth, Personal Ability and Social Status 11

2.1 Introduction . . . . . . . . . . . . . . . . 11

2.2 The model . . . . . . . . . . . . . . . . . . . . . 14

2.3 Society divided into students and non-students by wealth and ability . . 16

2.4 Status depends on the quantity of graduates . . . . . . . . . . 19

2.5 Who is in favor of tuition fees? . . . . . . . . . . . . 23

2.6 Example . . . . . . . . . . . . . . . . . . . . . . . . . 24

2.7 Conclusion . . . . . . . . . . . . . . . . 27

3 Honest Grading, Grade Inflation and Reputation 29

4 Academic Achievement and Tracking - A Theory Based on Grading Standards $\quad 30$

4.1 Introduction . . . . . . . . . . . . . . . . . . . . . 30

4.2 The model . . . . . . . . . . . . . . . 35

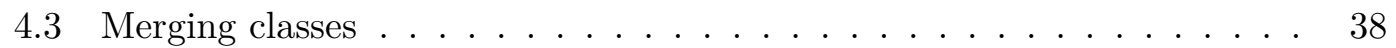

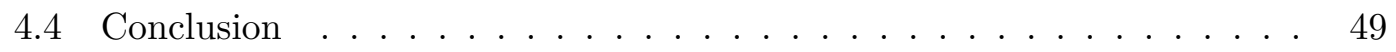

5 Concluding Remarks 


\section{List of Figures}

2.1 The utility as a function of income including wealth. . . . . . 15

2.2 The utility after study decision. . . . . . . . . . . . . . . 18

2.3 The students/non-students separating function. . . . . . . . . . 20

2.4 Social status, number of graduates and changing price. . . . . . . 21

2.5 Individual utility with an additive separable utility function. . . . . 25

2.6 Status dependent on the price to study. . . . . . . . . 26

2.7 Indifference line to study and reaction if the price changes. . . . . . . 27

4.1 Cost as a function of effort for a student. . . . . . . . . 36

4.2 The objective function of the comprehensive school. . . . . . . . . 39

4.3 Parameter regions in eagerness ability space, where optimal standards in the comprehensive school change. . . . . . . . . . . . . . 44 
Education is the most powerful weapon

which you can use to change the world.

\section{Introduction}

Nelson Mandela

Every generation builds on the fundament all former generations have created. Each is founded on human capital, like education, knowledge and competence, and physical capital, like infrastructure and production facilities. In this sense education is one of the main heritages a society can offer its next generation. That is why many people vote for free education, both in school and university, to make education affordable to everybody. Germany decided in the year 2008 at the "Bildungsgipfel" in Dresden to extend the spending to $10 \%$ of its gross domestic product (GDP) for Education and Research until 2015. Hetmeier, Schmidt, Vogel and Buschle (2015) in their yearly "Bildungsfinanzbericht" sum up, that the Budget in 2013 was 258.3 billion Euro (9.2\% of the GDP).

But why is education so important? On the one hand, it creates a mindset for understanding, liberty and free living, is therefore a pillar for a free democracy (e.g. Swanson and King 1991), and helps keeping a steady economic growth (e.g. Hanushek, Woessmann, Jamison and Jamison 2008). On the other hand, at the individual level, it will guarantee a better job and a good standing in society.

Even though this sounds quite plausible, people still seem to self-select into higher education and lower education not because of learning capacity, but because of their family background. It's often argued that free higher education is unfair, since the nurse pays with his or her tax the education of the chief physician's son. This indirectly implies that nurses' offsprings do not study (e.g. Ermisch and Francesconi 2001).

The modern field economics of education could not arise without the theory of human capital. Schultz (1963) was the first, who understood education as an investment in 
human capital. Analogous to a companys' decision to invest in new machines, people decide to invest in their education. After Schultz formulated these thoughts, a wide range of extensions has been published. Becker (1964) developed a detailed theory about human capital investment, with costs and returns. In addition, Parsons (1974) took imperfect capital markets into account, and Levhari and Weiss (1974) examined how risk relating to future incomes has an effect on human capital investments. There where many critics reminding Becker accusingly that the name "Human Capital" treats people as objects, like machines, but eventually the name and the work got accepted in research (Becker 1993).

Classical economic theory cannot explain the economic growth of the last century in Europe and other countries, like the US. The human capital theory closes this gap and explains the GDP growth with investment in human capital. For example, Denison (2011) explains about $25 \%$ of the growth between 1929 and 1982 with the investment into human capital, while he cannot assign the remaining growth. Hence, a lot more of the growth may be based on human capital expansion, which only cannot be identified.

From the governmental point of view, there is little influence on the decision to invest in human capital. Investment can only be raised by supporting schools and universities to make education affordable, or by making the school mandatory. Reducing the cost side could mean offering grants, subsidizing or building universities, and abolishing tuition fees. The government can raise the amount of scholarships and keep the interest rates for students loans low. Since overall resources in terms of tax revenues are limited, a decision has to be taken, if more investment in human capital or more investment in physical capital is beneficial. Investing into human capital is usually a long run investment, which takes about 20 years until a generation is grown up to pay off the investment.

The decision to invest in ones own human capital has to take a lot of lifetime spanning variables into account. The work of Mincer (1974) tries to evaluate the individual lifetime income, and how people would rationally decide to study or not to study depending 
on its costs and revenues. Mincer gives a detailed overview about which costs are relevant, and how to calculate a lifetime income. Of course, costs must include the direct out-of-pocket costs for the training, or, in case of studying, it must include tuition fees. But the costs need also include all the missed earnings while being educated. These opportunity costs consist of non-monetary ones, like missed leisure, and monetary ones, like missed wages. In the case of studying, the missed wages are in the scale of several years. On the individual level people decide if they want to extend their own amount of human capital investment by studying, going back to school (Cohn and Geske 1990), passing on-job trainings or extending knowledge during free time (Schultz 1982), all for the sake of getting a better personal future. This better future means higher wages, but can also mean non-monetary values, such as higher standing or status.

Chapter 2 of this thesis is based on my discussion paper (Ehlers 2011) and uses the idea of the rational calculation of costs and revenues for studying as base for a model. However, it will only focus on the differences tuition creates, while all the other values stay at a specific, unquantified level. The model includes the aforementioned second, non-monetary aspect of a degree, the social status or prestige. For wealthier people, the monetary aspects might play an inferior role, while a good standing is more important, since the social status can't be bought as such.

On first account it seems clear that nobody will vote for tuition if no surplus is expected by this money. On the other hand, can a student hope for others staying away from university by raising tuition fees? If this is the case, a university degree rises in its status value as the amount of degrees is artificially depleted. Then, just by having a university degree, one can await a higher social status without any further needs to delimit from others, for example by attaining good grades. Chapter 2 takes this correlation into account. It will introduce a model explaining the vote for tuition by wealthier and more able people, without relying on their expectation of a direct surplus from these tuitions. The wealthier people will always go to University, as the 
high tuition does not reduce their utility significantly, as a result of the diminishing marginal utility of money, but yields a relatively high utility in terms of status. Ultimately rasing status is so beneficial, that the costs for higher tuition is willingly incurred.

The social status derived from a universities' degree could also be seen as a signal for all actors in the surrounding of an university graduate, especially for employers, even though the model in chapter 2 did not make use of the signaling theory. In chapter 3 we use this theory, covering grade inflation and building upon a signaling game invented by Chan, Hao and Suen (2007), where universities send a signal regarding their distribution of good and mediocre students to employers. This chapter is based on the paper (Ehlers and Schwager 2016b), a joint work of Robert Schwager and myself.

Higher wages are paid for higher productivity, as investment in human capital. Having a degree is also a signal of other quality characteristics. Employers generally suppose better educated workers to live healthier and have lower incentives to quit or being absent (Weiss 1995). In short, a university degree not only signals higher productivity, but in addition better general characteristics. In the literature, the signaling theory is focusing on the signals every participant of an economy sends to others. The roots of this signaling theory can be found in the work of Spence (1973). He describes how good applicants for a job try to set themselves apart from inferior applicants. They use costly certificates as a signal, i.e. a degree. This fundamental work initiated a huge amount of related work using a signaling framework in modeling all kinds of economic relations.

The key concept of the signaling theory is information asymmetry between two types of market participants. The signal sender has valuable insider information, which could change the basis for decision-making of the receiver. The signal can contain a clue about the sending person itself (Spence 1973), a good (Kirmani and Rao 2000) or a company (Ross 1977) for example. The receiver as an outsider does not have this information, but would find it useful for his decision. With the signal from the sender the receiver can draw conclusions about the private information, but some uncertainty remains. 
For more information about the developement and concept of the signaling theory, see Connelly, Certo, Ireland and Reutzel 2011.

Attending a university does not guarantee a degree. In all branches there is a positive drop-out rate. For a university it would be easy to lower this rate, it just needs to lower the standard. This is called grade inflation. Generally, one speaks of grade inflation, when good grades are granted for less performance over time. When searching for the cause of this trend, it is often assumed that grade inflation is costless for the university. Grades are seen as a kind of a cheap talk. And since awarding good grades is costless for an individual school and additionally has the advantage of attracting students, and thereby generating more tuition, it seems that grade inflation is unavoidable. But in fact, when people are attracted by the expectation of good grades for an average performance, it is already generally known that this institution inflates grades, which in the next step has negative impact on the university's reputation, and finally have repercussions on the labor market.

In the model introduced in chapter 3 the amount of students, and how many of them are good is given exogenously. In the signaling game of Chan, Hao and Suen (2007), the school sends a signal to the labor market about its amount of good students in terms of the amount of $A$ s awarded. This amount of $A$ s does not correspond to the amount of good students, when grades are inflated or deflated. The labor market will pay a wage corresponding to the expected average performance to the students. In case of a low endowment of good students, the school needs to trade off between the higher wage of good students with an $A$, when grading honestly, and the lower wage of (good and a part of the mediocre) students who received an $A$, when inflating grades.

The result from Chan, Hao and Suen (2007) is, that honest grading is never reasonable. We show that this result can be traced back to the layout of the game, where grade inflation has no influence on the reputation of the school. We extended the model to have a second cohort of students. These students will appear in the game when the grading policy of the school is already generally known and therefore will be employed 
when the labor market already knows about the grading policy of the school, which we call reputation of the school. Of course the size of this cohort crucially drives the findings. Having a larger second cohort, the impact on reputation is higher. The chapter 3 proves that including reputation endogenously reduces grade inflation, and honest grading can also lead to a reasonable equilibrium.

Policy makers who are chasing for the noble goal to give everybody the affordable chance to attend a university, fight against grade inflation and stand for equality of opportunity, must think of the institutional question of how schools should handle unequally abled students. Many countries, like Germany, implement early tracking and therefore separate students into different ability tracks at a very early state. Other countries, like the US, try to keep all kinds of students together, tracking in individual subjects, at the most. Does it help mediocre students to be taught together with good students? Are good students hampered?

Chapter 4 deals with the question whether unequally abled students should be placed in one class or should be taught separately and is based on the discussion paper (Ehlers and Schwager 2016a), another joint work of Robert Schwager and myself. We step back from signaling theory and sketch a simple model with basic economic behavioral assumptions, generally based on the idea of Costrell (1994). Our model cancels out the aspect of different performance, depending on the ability of the teacher (e.g. Rivkin, Hanushek and Kain 2005). We introduce a two dimensional performance measure. One dimension measures the ability from previous learning and the other one measures the eagerness for learning and ability to quickly understand new contexts. In the first years in school the endowment of previous knowledge can also be seen as a kind of socioeconomic background. The model we introduce focuses on teachers' demand or standard and the performance reaction of the students. We state that tracked classes are always better off in this aspect compared to mixed classes or comprehensive school, when all actors share the same objective function, since the teacher can individually set 
an optimal demand. The crucial point here is the assumption that teacher and students take effort costs into account, while parents, or at least society and research, do not.

Our main finding is that in the comprehensive school the measured performance of the less able students can increase, even if there are no direct synergy effects from teaching different students together. This arises because the comprehensive school sets a compromise standard, which exceeds the standard from the low ability track. Moreover, if students with lower initial ability have higher eagerness to learn, merging classes will increase average performance. And this, in turn, could lead to the impression that comprehensive schools help low ability students, while they are in fact overstrained and mean performance increases.

As outlined, in this thesis I focus on topics in the area of economics of education. We contribute three theoretical models to the existing literature. Our specific research questions can be summarized as follows:

1. Do university tuition fees skew incentives for a degree?

2. Can status concerns explain the existence of tuition fees?

3. Can honest grading be reasonable in a signaling world with reputation?

4. If grade inflation exists in equilibrium, is the probability dependent on the importance of reputation?

5. Do comprehensive schools yield profit for low achieving students?

6. Is a tracked schooling system harmful or beneficial?

The first model, presented in chapter 2, will explain effects from tuition fees on enrollment rates and answers question 1 and 2. The second one (see chapter 3), will focus on grade inflation and the reputational effect and is assessing question 3 and 4, while the last model, developed in chapter 4, will show the relationship of comprehensive school and tracked school to student performance addressing question 5 and 6 . 


\section{University Graduation and its Dependency on Family Wealth, Personal Ability and Social Status}

Author: Tim Ehlers

\section{$2.1 \quad$ Introduction}

There is no doubt that tuition fees have been the subject of heated debate in many countries in recent years. If fees should be introduced, increased or abolished have been especially considered. For instance, tuition fees have always been charged in the US and range from 3,000 to 40,000 dollars per year. England allowed universities to increase their tuition fees charged from the maximum of 1,000 pounds to 3,000 pounds per year in 2005 (Frankfurter Allgemeine Zeitung (2005)). The House of Commons gave permission to increase the fees to up to 9,000 pounds starting in 2012: this was accompanied by heavy student protests (Frankfurter Allgemeine Zeitung (2010)). The reform of federalism in Germany in 2006 led to several readjustments in the distribution of the authority between the states and the federal government. The authority for education was largely shifted to the individual states. Accordingly, seven German states introduced tuition fees in this move. However, in the meantime all of them have returned to a free system, at least for the first degree.

By charging tuition fees, the number of students may decline, leading to a higher 
reputation of the university degree. Huebner (2012) shows a small but significant reduction in the enrollment rates of seven German states after the introduction of a 1,000 Euro fee per year. The present chapter assumes the scarcity of students as the basis for the improvement of the status obtainable by graduation. As a result of this assumption, it may well be that not only the more gifted students but also the persons of means could enjoy high reputation by an enforced reduction of the number of students. The richer people vote for a tuition fee, even though this does not improve the quality of education, in order to archive this.

As opposed to Heckman (1976) who introduced a model in which investment in human capital results in better allocation of leisure, and thus increasing "private" utility, the present chapter introduces a model that describes an independent non-monetary utility increase, making people more inclined to study at university. Attaining a higher academic degree is usually combined with higher reputation in everyday life and in interaction with non academic people. The possible reasons for this higher reputation are diverse. One could argue that an academic degree is not only a signal for high ability but also stamina and other positive but hidden properties. The independent variable in this model is the social status or the prestige being attained with a university degree. Nonetheless, the model can also cover additional non-monetary factors, for example an occupation fitting better to personal disposition and the joy of learning or enjoying student's life. For the model, it is not necessary to declare what the status is concretely. The only important fact is a non-monetary influence on utility by graduating.

Within the controversial debate for and against tuition fees, people in favor of the fees often mention the raised quality as benefit to the students because the university has more money available for improving study conditions. Schwager (2008) presents a model in which solely the state runs universities. The state chooses the quality with a trade-off between the value of local immobile students and the cost of running the universities. The higher the tuition the lower the state's net costs to manage the universities. This rule ends when the number of enrolled students decreases too much. This chapter does 
not take the quality effect into account to simplify the model. Since all students would more or less benefit from better study conditions, this would only likely shift the opinion of the more able students towards higher fees.

Another model, presented by Kemnitz (2010), deals with the decision to study or not to study and describes the utility function as being dependent on lifetime income. This model deals with the abolition of the ban on tuition fees. The author assumes a relationship between the quality effect for higher education and the amount of tuition fees.

Gary-Bobo and Trannoy (2008) present a signaling model in which universities are social surplus maximizers or profit maximizers. One would presume universities as social surplus maximizers, when assuming a welfare state and universities driven by the state. The students' decision to study depends on their wage surplus from studying, which in turn depends on their intellectual ability.

From social planers' point of view, there are two mechanisms for selecting students: exams and fees. Del Rey (2009) developed a model showing that if there is only a state university, the social surplus maximizing planer would choose exams over fees. Del Rey (2009) also shows that with competing private and state universities with perfect credit market, the optimal fees could be positive.

People maximize their own utility by maximizing their lifetime income with subtracted costs of study (Schultz (1961)). In other words, the young people estimate the benefits and efforts of "purchasing" a university degree. This is referred to as the investment approach (Campbell and Siegel (1967)). The costs of study include the effort of passing exams, but also different costs of living, books and opportunity costs in the form of income loss during the years of study. In the end, the investment must raise the individual utility compared to the decision not to study. However, this utility differs between richer and poorer families. Rich people would value the effort to study higher than poor people would and they value the utility loss of paying tuition fees lower than poor people would do. 
Becker (1975) developed a detailed theory about human capital investment with costs and returns. The model in this chapter simplifies the details by summarizing the variables for costs and earnings in a single variable.

Costs include tuition fees for attending university. This chapter focuses on these tuition fees. It introduces a model which may help to explain a possible incentive of some classes within the society to impose a levy on the attendance of universities, fixing the fees at a level as high as possible. The assumption is that richer people are more interested in obtaining a high social status and therefore in raising their utility by obtaining prestige, on the other hand poor people are firstly concerned in extending their finances.

\subsection{The model}

In the model each student or non-student has a family, but no siblings or children. Each family has accumulated wealth of an individual value $w$. The student's utility consists of two variables: the first is the wage or income $y$ he gets during his lifetime including $w$ (this can be interpreted as income through inheritance) and the second one is called the social status or prestige $s$. This variable adopts two values: 0 if the person doesn't study and a positive value when the person graduates (to study and fail is not an option). A student $i$ has an individual utility function:

$$
U_{i}=U\left(y_{i}, s_{i}\right) .
$$

A student may value these two variables $(y, s)$ in different ways. The assumption is that the assessment depends on family's wealth. As stated before, this wealth $(w)$ is included in the lifetime income $y$. The higher the lifetime income, the more the student will value the benefit of the status. The poorer the family, the more the person will value the higher income. Therefore, the utility of any student can be expressed as a function dependent on $y$ and $s[U(y, s)]$ as shown in Figure 2.1. The assumptions are 
$\frac{\partial^{2} U(y, s)}{\partial y \partial s}>0$ and $\frac{\partial^{2} U(y, s)}{\partial y^{2}}<0$. However, as we will see later, the results still hold, if we relax the first assumption to $\frac{\partial^{2} U(y, s)}{\partial y \partial s} \geq 0$ and allow the same utility increase in $s$ for any person.

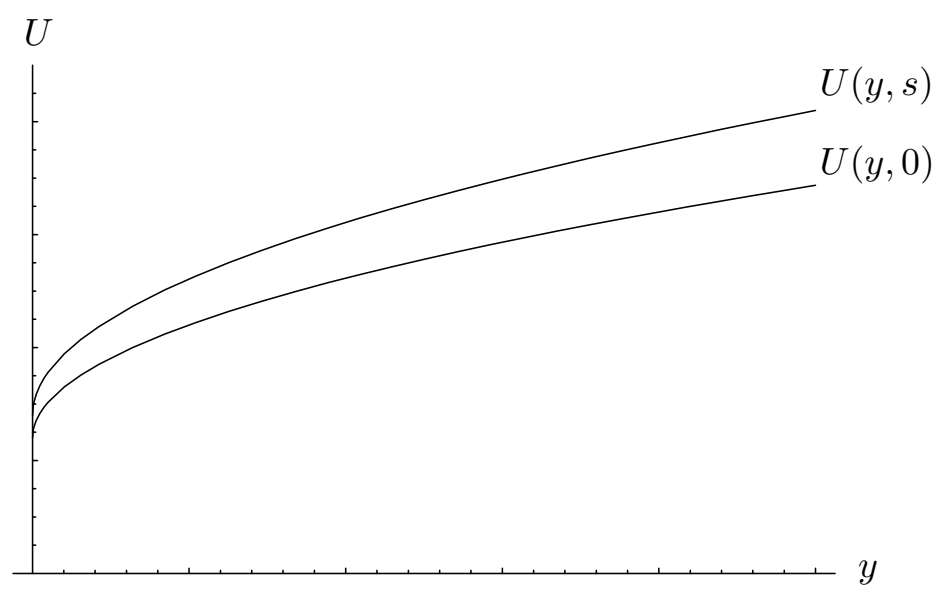

Figure 2.1: The utility $U$ as a function of $y$ (income including wealth) with and without a fixed value of the social status $s ; \frac{\partial^{2} U(y, s)}{\partial y \partial s}>0$.

For the years of study, all students pay an amount $p$ for studying, including tuition fees. After studying, they may get a higher income $\alpha \Delta y$ compared to the income they would earn without studying. The $\Delta y$ should be understood as the (minimum) difference in lifetime income, discounted to a specific time. This chapter doesn't concentrate on interest rates or taxes, so $\Delta y$ will be treated as a fixed value. $\Delta y$ should also be understood as a actuarial expectation value with decision under uncertainty. No student can be sure to get a better paid job after studies. Nevertheless, since persons can have different abilities, the later income also depends on the individual ability level $\alpha \in[1, \overline{\bar{\alpha}}]$. The variable $\alpha$ can be interpreted as higher income through better grade, faster study, and therefore a longer income period or just to receive a better paid job with good results in the assessment center. The utility function for any student is a function given by $y=w+\alpha \Delta y-p$ and the non-monetary value $s$ :

$$
U=U(w+\alpha \Delta y-p, s) .
$$


Any person not studying has a utility given by:

$$
U=U(w, 0)
$$

\subsection{Society divided into students and non-students by wealth and ability}

There is a continuum of students ordered by wealth and ability. The number of students is normalized at unity with density function $f(w, \alpha)$ and distribution function $\int_{1}^{\overline{\bar{\alpha}}} \int_{0}^{\overline{\bar{w}}} f(w, \alpha) d w d \alpha$, where $\overline{\bar{w}}$ is the richest characteristic and $\overline{\bar{\alpha}}$ is the most able characteristic in society.

Proposition 2.1 If there are individuals not studying at a given ability $\bar{\alpha}$, and if not all individuals with this ability reject studying, there is one $\widetilde{w}$ where for a given $p$, all young people sort themselves into two groups such that one group with the size $\int_{0}^{\widetilde{w}} f(w, \bar{\alpha}) d w$ are persons not studying. The other group with size $\int_{\tilde{w}}^{\overline{\bar{w}}} f(w, \bar{\alpha}) d w$ are students.

Proof. The cross-derivative $\frac{\partial^{2} U(y, s)}{\partial y \partial s} \geq 0$ must hold (richer people have the same or higher marginal utility from social status, see Figure 2.1 showing $\frac{\partial^{2} U(y, s)}{\partial y \partial s}>0$ ), so that there is one threshold dividing the persons by wealth $w$. Firstly, consider a student indifferent between studying and not studying. His wealth is $w=\widetilde{w}$. Therefore, the utility shown below must hold:

$$
U(\widetilde{w}+\bar{\alpha} \Delta y-p, s)=U(\widetilde{w}, 0) .
$$

Now, consider a student whose wealth is above the threshold, $w>\widetilde{w}$. The utility is

$$
U(w+\bar{\alpha} \Delta y-p, s)=U(\widetilde{w}+\bar{\alpha} \Delta y-p, s)+\int_{\widetilde{w}}^{w} \frac{\partial U(z+\bar{\alpha} \Delta y-p, s)}{\partial z} d z
$$


if he studies and

$$
U(w, 0)=U(\widetilde{w}, 0)+\int_{\widetilde{w}}^{w} \frac{\partial U(z, 0)}{\partial z} d z
$$

if he doesn't. The difference in the utilities is:

$$
\begin{aligned}
& U(w+\bar{\alpha} \Delta y-p, s)-U(w, 0) \\
& \quad=U(\widetilde{w}+\bar{\alpha} \Delta y-p, s)-U(\widetilde{w}, 0)+\int_{\widetilde{w}}^{w}\left[\frac{\partial U(z+\bar{\alpha} \Delta y-p, s)}{\partial z}-\frac{\partial U(z, 0)}{\partial z}\right] d z .
\end{aligned}
$$

The first two terms on the right hand side are equal because a person with $w=\widetilde{w}$ is indifferent between studying and not studying (see (2.3)). Therefore,

$$
U(w+\bar{\alpha} \Delta y-p, s)-U(w, 0)=\int_{\widetilde{w}}^{w}\left[\frac{\partial U(z+\bar{\alpha} \Delta y-p, s)}{\partial z}-\frac{\partial U(z, 0)}{\partial z}\right] d z .
$$

If $\frac{\partial^{2} U(y, s)}{\partial y \partial s} \geq 0$ holds,

$$
\frac{\partial U(y, s)}{\partial y} \geq \frac{\partial U(y, 0)}{\partial y}
$$

The marginal utility of money $(y)$ decreases, $\frac{\partial^{2} U(y, s)}{\partial y^{2}}<0$ and $\bar{\alpha} \Delta y<p$ (otherwise the indifference in (2.3) would not hold):

$$
\frac{\partial U(w+\bar{\alpha} \Delta y-p, s)}{\partial y}>\frac{\partial U(w, s)}{\partial y}
$$

Comparing (2.5) and (2.6) with the inner square bracket of (2.4) shows that

$$
\frac{\partial U(w+\bar{\alpha} \Delta y-p, s)}{\partial y}>\frac{\partial U(w, s)}{\partial y} \geq \frac{\partial U(w, 0)}{\partial y}
$$

and hence $(2.4)>0$ for all $y \in(\widetilde{w}, w]$. So any student with $w>\widetilde{w}$ will study. By analogous argument, one can conclude that all individuals with $w<\widetilde{w}$ choose not to study. 


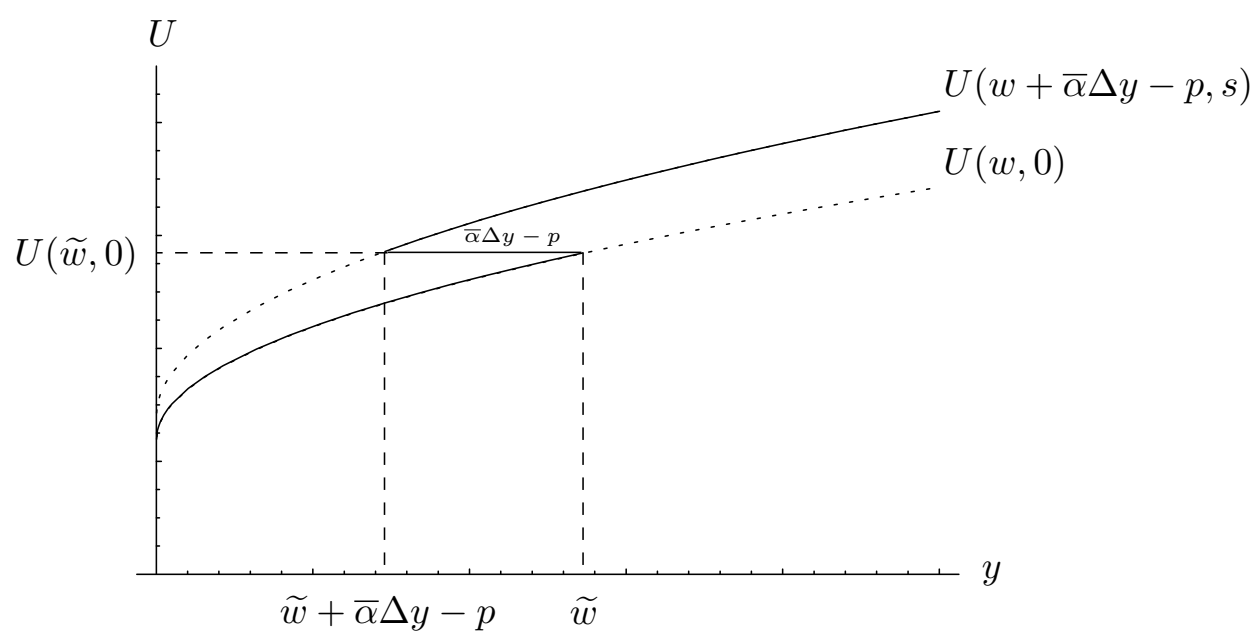

Figure 2.2: The utility after study decision below $\widetilde{w}$ and above.

Figure 2.2 shows the functions $U(w, 0)$ and $U(w+\bar{\alpha} \Delta y-p, s)$. All individuals with $w<\widetilde{w}$ choose not to study and get the utility of $U(w, 0)$. For a given $\bar{\alpha} \Delta y-p<0$, there is one indifferent person with $w=\widetilde{w}$ getting the same utility on both functions: $U(\widetilde{w}, 0)=U(\widetilde{w}+\bar{\alpha} \Delta y-p, s)$. All people with $w>\widetilde{w}$ are getting a higher utility on the function $U(w+\bar{\alpha} \Delta y-p, s)$ than on the function $U(w, 0)$.

With $\bar{\alpha}$, all investigated persons are assumed to have the same intellectual ability, but the society consists of persons with different abilities, $\alpha \in[1, \overline{\bar{\alpha}}]$. The indifferent person must have an $\alpha=\widetilde{\alpha}$, so that $p$ is higher than $\widetilde{\alpha} \Delta y$. If $\widetilde{\alpha} \Delta y$ is higher or equal $p$, there will be no one indifferent, because as per definition, the social status is positive and anybody with this intellectual ability would study independently of his monetary background (see fig. $2.2, \bar{\alpha} \Delta y-p<0$ ).

If there are individuals not studying at a given wealth $\bar{w}$, and if not all the individuals with this wealth reject studying, there will also be one $\widetilde{\alpha}$, where for a given $p$, all young people sort themselves into two groups, where the more able people choose to study.

Proposition 2.2 There is a bijective relation between $\widetilde{\alpha}$ and $\widetilde{w}$. This function, $\widehat{w}(\alpha)$ 
or $\widehat{\alpha}(w)$, has a negative slope, where $0<w<\overline{\bar{w}}$ and $1<\alpha<\overline{\bar{\alpha}}$ :

$$
\begin{aligned}
& \widehat{w}(\alpha)= \begin{cases}\widetilde{w}(\alpha) & \text { if } \widetilde{w}(\alpha)>0, \widetilde{w}(\alpha)<\overline{\bar{w}} \\
\overline{\bar{w}} & \text { if } \widetilde{w}(\alpha)>\overline{\bar{w}} \\
0 & \text { if } \widetilde{w}(\alpha)<0\end{cases} \\
& \widehat{\alpha}(w)= \begin{cases}\widetilde{\alpha}(w) & \text { if } \widetilde{\alpha}(w)>0, \widetilde{\alpha}(w)<\overline{\bar{\alpha}} \\
\overline{\bar{\alpha}} & \text { if } \widetilde{\alpha}(w)>\overline{\bar{\alpha}} \\
0 & \text { if } \widetilde{\alpha}(w)<1 .\end{cases}
\end{aligned}
$$

Proof. The generalized indifference condition from 2.3$)(\bar{\alpha} \equiv \widetilde{\alpha})$ defines an implicit function $\widehat{\alpha}(w)$ with derivative:

$$
\frac{d \widehat{\alpha}}{d w}=-\frac{\frac{\partial U(\widetilde{w}+\widetilde{\alpha} \Delta y-p, s)}{\partial y}-\frac{\partial U(\widetilde{w}, 0)}{\partial y}}{\frac{\partial U(\widetilde{w}+\widetilde{\alpha} \Delta y-p, s)}{\partial y} \Delta y}
$$

The denominator of 2.10 is positive, because money always increases utility and $\Delta y$ without the costs of the studies are also positive. The numerator is also positive if $\widetilde{\alpha} \Delta y-p<0$. This means that in the normal case, with existence of an indifferent person, $2.10<<0$. So there is an indifference function $\widehat{\alpha}(w)$ with a negative slope. The inverse function $\widehat{w}(\alpha)$ can be proven analogous. $\square$

This bijective function is shown in figure 2.3(a) as $\widehat{\alpha}(w)$.

\subsection{Status depends on the quantity of graduates}

The status $(s)$ was treated as a fixed positive value until now. Now, assume that $s$ depends on the number of graduates $(l)$. The more graduates the economy has, the less prestige one will derive from graduating. This direct relation is denoted by $S(l)$, $S^{\prime}(l)<0$. From the individuals' point of view, we get the opposite relation. When $s$ increases, $\widetilde{w}$ decreases and with decreasing $\widetilde{w}$, the share of students $(l)$ will increase. 


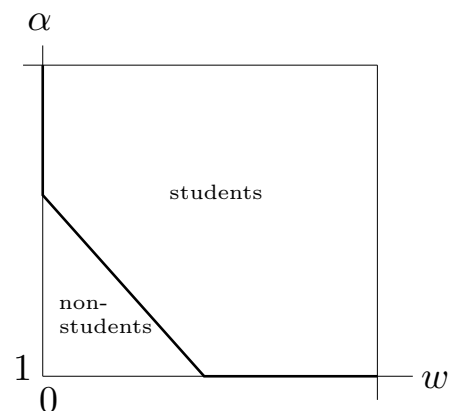

(a) The indifference-relation between $\alpha$ and $w$.

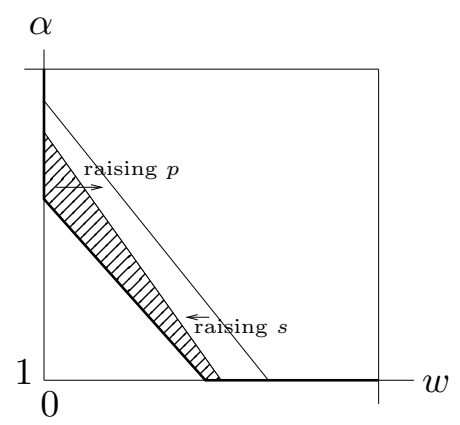

(b) The indifference-relation between $\alpha$ and $w$, raises $\mathrm{p}$, then raises s.

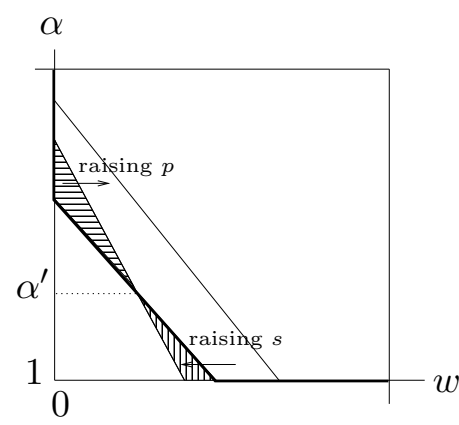

(c) The same reaction like 2.3(b) but the richest indifferent person is now better off after rasing $p$. The horizontally hatched area must be bigger than the vertically hatched area.

Figure 2.3: The students/non-students separating function, dependent on $\alpha$ and $w$. The area above the line shows the share of students in society. The area below represents the share of non-students.

The relation is expressed by $l\left(S_{U}\right)$, or for better comparison the inverse of $l\left(S_{U}\right), S_{U}(l)$. In the static equilibrium, all people with specific $\alpha$ and $w$, which in combination leads to a higher status when graduating, will study and graduate. This can be expressed as $l=\int_{1}^{\overline{\bar{\alpha}}} \int_{\widehat{w}(\alpha)}^{\overline{\bar{w}}} f(w, \alpha) d w d \alpha$, where $\widehat{w}(\alpha)$ is the students/non-students separating function 2.8), see also figure $2.3(\mathrm{a})$.

In Figure 2.4(a), these static equilibrium relations are shown. For the high status $s^{\prime}$ a specific low $\widetilde{w}$ will be established with the corresponding high number of students $l^{\prime}$. However, this number of students will establish the low status $s^{\prime \prime}$ in society. In equilibrium, $s^{*}$ and $l^{*}$ will be established.

For the analysis of the simultaneous equilibrium, two equations must hold:

$$
\begin{aligned}
l-L(s, p) & =0, \\
s-S(l) & =0 .
\end{aligned}
$$

Here, $L(s, p)=\int_{1}^{\overline{\bar{\alpha}}} \int_{\widehat{w}(\alpha)}^{\overline{\bar{w}}} f(w, \alpha) d w d \alpha$, corresponding to the $S_{U}(l)$ function.

What happens to $S_{U}(l)$ if $p$ changes or, in other words, if $S_{U}(l)$ is shifted, where is 


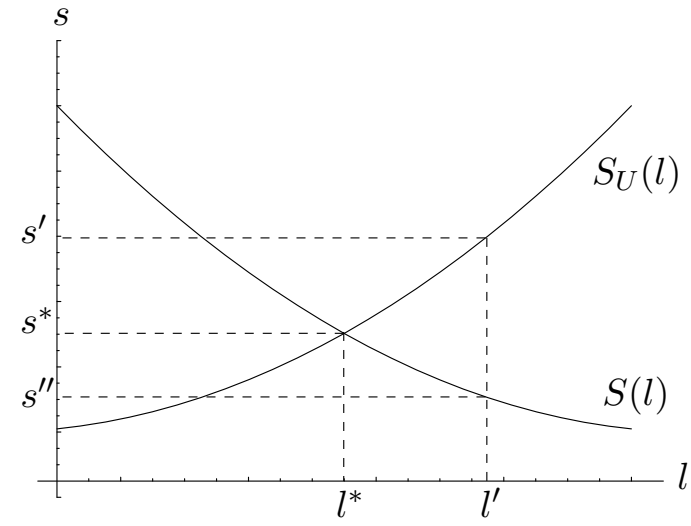

(a) Status $s$ established by the society $(S(l))$ and an indirect function $\left(S_{U}(l)\right)$, showing how many persons would study, dependent on the status $s$.

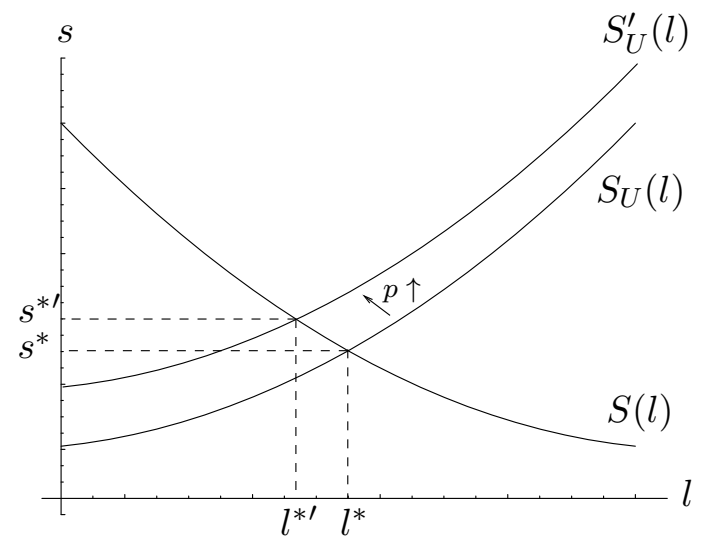

(b) Scrolling $S_{U}(l)$ by raising $p$. A new equilibrium at $\left(l^{* \prime}, s^{* \prime}\right)$ is established.

Figure 2.4: Dependencies between social status, number of graduates and changing $p$. Where status and number of students are derived endogenously within a simultaneous equilibrium.

the new simultaneous equilibrium $s^{*}(p)$ ? From total differential of 2.11) and 2.12

$$
\begin{aligned}
d l-\frac{\partial L}{\partial s} d s-\frac{\partial L}{\partial p} d p & =0 \\
d s-\frac{\partial S}{\partial l} d l & =0
\end{aligned}
$$

We derive:

$$
\frac{d s^{*}(p)}{d p}=\frac{\frac{\partial S}{\partial l} \frac{\partial L}{\partial p}}{1-\frac{\partial L}{\partial s} \frac{\partial S}{\partial l}} .
$$

Proposition 2.3 A raise in price will lead to a higher status in equilibrium and vice versa. In other words $\frac{d s^{*}(p)}{d p}>0$.

Proof. The crucial parts are the changes in $L(s, p)$ with respect to $s$ and $p$. Firstly, we look at $\frac{\partial L}{\partial s}$ :

$$
\frac{\partial L}{\partial s}=\int_{1}^{\overline{\bar{\alpha}}} \frac{\partial A(\alpha, \widehat{w}(\alpha, s, p))}{\partial s} d \alpha
$$


with $A(\alpha, \widehat{w}(\alpha, s, p))=\int_{\widehat{w}(\alpha, s, p)}^{\overline{\bar{w}}} f(w, \alpha) d w$, the share of students for a given $\alpha$. From the partial $\frac{\partial A}{\partial s}=\frac{\partial A}{\partial \widehat{w}} \frac{\partial \widehat{w}}{\partial s}$, we derive:

$$
\frac{\partial A}{\partial s}=-f(\widehat{w}(\alpha, s, p), \alpha) \frac{\partial \widehat{w}(\alpha, s, p)}{\partial s} .
$$

From indifference constraint 2.3 , we derive for $\frac{d \widehat{w}}{d s}$ for the interior solution $(\widehat{w}=\widetilde{w})$ :

$$
\frac{d \widehat{w}}{d s}=-\frac{\frac{\partial U(\widehat{w}+\alpha \Delta y-p, s)}{\partial s}}{\frac{\partial U(\widehat{w}+\alpha \Delta y-p, s)}{\partial y}-\frac{\partial U(\widehat{w}, 0)}{\partial y}} .
$$

If $\widehat{w}=0$, the reasons are there is no indifferent person $\widetilde{w}$ at this $\alpha$ (all people having this $\alpha$ will study) or because $\widehat{w}$ already reached maximum $\overline{\bar{w}}, \frac{d \widehat{w}}{d s}=0$ and therefore $\frac{\partial L}{\partial s}=0$ :

$$
\frac{d \widehat{w}}{d s}= \begin{cases}-\frac{\partial U(\widehat{w}+\alpha \Delta y-p, s)}{\partial s} & \text { if } \widehat{w}=\widetilde{w} \\ \frac{\partial U(\widehat{w}+\alpha \Delta y-p, s)}{\partial y}-\frac{\partial U(\widehat{w}, 0)}{\partial y} & \text { if } \widehat{w}=0, \text { or } \widehat{w}=\overline{\bar{w}}\end{cases}
$$

The whole effect over all $\alpha$ can be written as:

$$
\frac{d L}{d s}=\int_{1}^{\alpha_{0}(s, p)} f(\widehat{w}(\alpha, s, p), \alpha) \frac{\frac{\partial U(\widehat{w}+\alpha \Delta y-p, s)}{\partial s}}{\frac{\partial U(\widehat{w}+\alpha \Delta y-p, s)}{\partial y}-\frac{\partial U(\widehat{w}, 0)}{\partial y}} d \alpha
$$

Here $\alpha_{0}(s, p)$ is that $\alpha$, where the indifferent person is just not existent anymore $(\widehat{w}(\alpha, s, p)=0)$.

$\frac{\partial L}{\partial p}$ can be expressed in a similar way:

$$
\frac{d L}{d p}=\int_{1}^{\alpha_{0}(s, p)}-f(\widehat{w}(\alpha, s, p), \alpha) \frac{\frac{\partial U(\widehat{w}+\alpha \Delta y-p, s)}{\partial y}}{\frac{\partial U(\widehat{w}+\alpha \Delta y-p, s)}{\partial y}-\frac{\partial U(\widehat{w}, 0)}{\partial y}} d \alpha .
$$

Now we can value the sign of 2.13 . Since $\frac{\partial L}{\partial p}<0$ and $\frac{\partial S}{\partial l}<0$, the numerator is positive. The denominator is also positive since $\frac{\partial L}{\partial s}>0$ and $\frac{\partial S}{\partial l}<0$. This means that if $p$ rises, the amount of students must decline, and therefore $s$, in equilibrium, is rising. $\square$ 


\subsection{Who is in favor of tuition fees?}

When $p$ is not given exogenously, but can be set, for example by majority vote, the question arises: who could have an interest in raising or lowering $p$ ? In other words, who is a loser and who is a winner when $p$ is increased? The utility function is redefined as being dependent on $w, \alpha$ and $p$, where equilibrium status is endogenously determined by $p$ according to (2.11) and 2.12).

$$
V(w, \alpha, p) \equiv U\left(w+\alpha \Delta y-p, s^{*}(p)\right) .
$$

Differentiating $V(w, \alpha, p)$ with respect to $p$ gives:

$$
\frac{\partial V}{\partial p}=-\frac{\partial U\left(w+\alpha \Delta y-p, s^{*}(p)\right)}{\partial y}+\frac{\partial U\left(w+\alpha \Delta y-p, s^{*}(p)\right)}{\partial s^{*}(p)} \frac{d s^{*}(p)}{d p} .
$$

The first part of the equation is the direct effect on utility for lowering the wealth or for raising fees. The second term is the effect on utility for the indirect rise of status multiplied with the actual rise in $s$. The total effect on utility depends on the strength of both effects:

$$
\frac{\partial V}{\partial p}\left\{\begin{array}{cc}
>0 & \text { if } \frac{\partial U\left(w+\alpha \Delta y-p, s^{*}(p)\right)}{\partial s^{*}(p)} \frac{d s^{*}(p)}{d p}>\frac{\partial U\left(w+\alpha \Delta y-p, s^{*}(p)\right)}{\partial y} \\
<0 & \text { if } \frac{\partial U\left(w+\alpha \Delta y-p, s^{*}(p)\right)}{\partial s^{*}(p)} \frac{d s^{*}(p)}{d p}<\frac{\partial U\left(w+\alpha \Delta y-p, s^{*}(p)\right)}{\partial y}
\end{array}\right.
$$

The higher $w$, the lower the income effect $\frac{\partial U\left(w+\alpha \Delta y-p, s^{*}(p)\right)}{\partial y}$ and the higher the effect on utility by rising status. In the upper part of the old indifference line (Figure 2.3(a)) the former indifferent person would be a loser in raising $p$, if he would have studied. However, since he was indifferent, he can switch to no-study. If the crowding out effect for the poorer people is high enough, situation shown in Figure 2.3(c) can occur. Then, the richer indifferent persons would win in rising $p$.

In the situation in Figure 2.3(b) there are five groups in society now. The group of 
people who are poorer than $\widetilde{w}(\alpha)$ don't care about the fees. They don't study anyway and don't win or lose when $p$ rises. The second group ranges from $\widetilde{w}(\alpha)$ to the indifference point of the new indifference function. They become losers when $p$ increases. They change their decision for study. They would have studied before the rise and will now decline to study. They lose utility by the amount of $U\left(w+\alpha \Delta y-p^{o}, s^{o *}(p)\right)-U(w, 0)$ $\left({ }^{o}=\right.$ old value). The third group still studies, but the price-effect is higher than the status effect (see $(2.21), \frac{\partial V}{\partial p^{\circ}}<0$ ). The fourth group had an incentive to raise $p$, but not as much as it has been raised $\left(\frac{\partial V}{\partial p}<0<\frac{\partial V}{\partial p^{\circ}}\right)$. They are now against further raising of the fees. The fifth group win after the raise: their price-effect is lower than the gain on rising status.

In the situation in Figure 2.3(c), with $\alpha>\alpha^{\prime}$, we have the same five groups. For the indifferent person with $\alpha=\alpha^{\prime}$, the status effect exactly cancels the price effect out. However, this does not mean that there is no winner in increasing $p$. Since the status is higher than before, the utility function is steeper now. All people with $w\left(\alpha^{\prime}\right)>\widetilde{w}\left(\alpha^{\prime}\right)$ are winners in raising $p$. On this level of $\alpha$, there are no losers in raising $p$ : this applies for all $\alpha \leq \alpha^{\prime}$. This means that in the situation in Figure 2.3(c) there is a big winning group when $p$ is raised. This group includes all students with $\alpha \leq \alpha^{\prime}$, but also a number of students with $\alpha>\alpha^{\prime}$ with higher wealth.

Nonetheless, even if the normal reaction (Figure 2.3(b) occurs, there can be a group in the right region (the rich part of society) gaining more from higher status than losing from higher prices for university. If there exists such a group, then how big it is depends on the disparity of wealth in the society.

\subsection{Example}

For the example, I choose an additive separable utility function:

$$
U(y, s)=\ln (y+1)+\ln (s+1),
$$




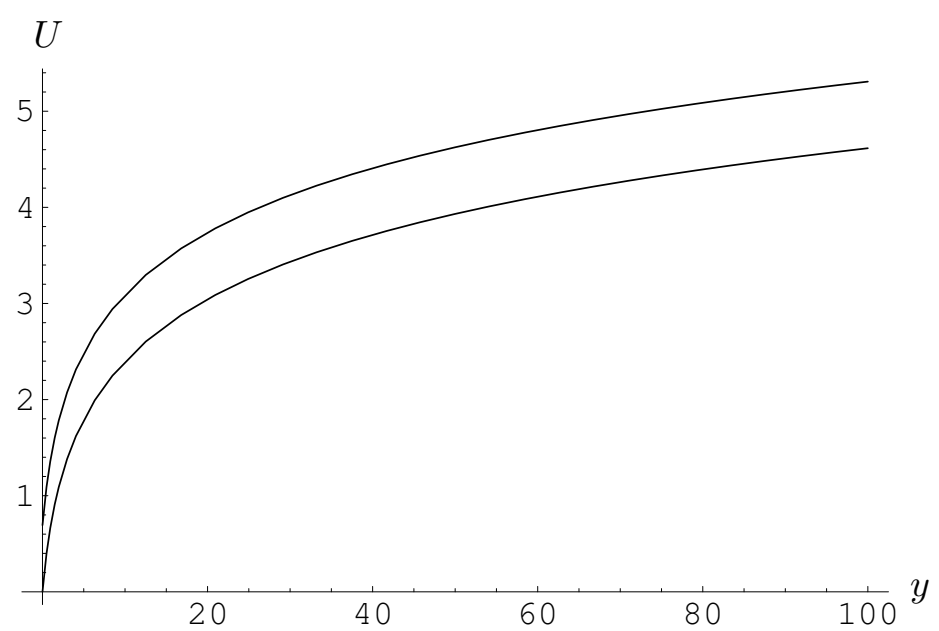

Figure 2.5: Individual utility, dependent on $y$, with $s=1(U(y, s)=\ln (y+1)+\ln (2)$ and $U(y, 0)=\ln (y+1))$.

$$
\begin{aligned}
& \frac{\partial^{2} U}{\partial^{2} y}=\frac{-1}{(y+1)^{2}}, \\
& \frac{\partial^{2} U}{\partial y \partial s}=0 .
\end{aligned}
$$

The individual's income when studing equals:

$$
y=w+\alpha \Delta y-p .
$$

The individual's income without the decision to study is denoted by:

$$
y=w .
$$

For an individual in an economy with $s=1$, the utility functions dependent on $y$ and can be found in Figure 2.5. Since I modeled an additive separable utility function, there is just a shift and no rotation between the function to study and not to study. With 
presumable non negative and non zero utilities, the indifference can be expressed as:

$$
\begin{array}{ll}
\ln (\widetilde{w}+\alpha \Delta y-p+1)+\ln (s+1) & =\ln (\widetilde{w}+1) \\
(\widetilde{w}+\alpha \Delta y-p+1)(s+1) & =\widetilde{w}+1
\end{array}
$$

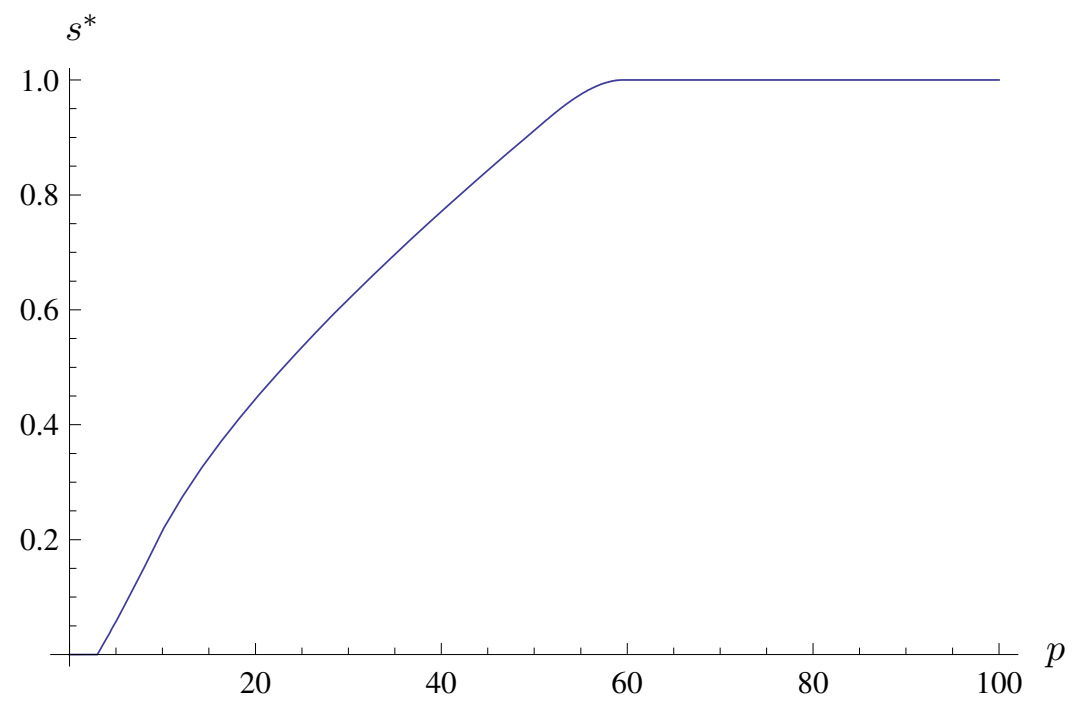

Figure 2.6: Status dependent on the price to study, $\Delta y=3,1 \leq \alpha \leq 3,0 \leq w \leq 100$.

In the example I assume $\alpha$ between 1 and 3 and $w$ between 0 and 100. For simplicity, I assume an uniform distribution over all $\alpha$ and $w$. Hence, the social functions can be expressed as follows:

$$
\begin{aligned}
L_{U}(s, p) & =\int_{1}^{3} \int_{\widehat{w}(\alpha)}^{100} \frac{1}{200} d w d \alpha, \\
L(s) & =1-s .
\end{aligned}
$$

The income difference $\Delta y$ is set to 3 . There is a status function dependent on the price to study (Figure 2.6. The status is 0 until the price raises above 3 , because with $p \leq 3$ even the most unable person would gain (or at least does not lose) from studying 
independently of his family wealth.

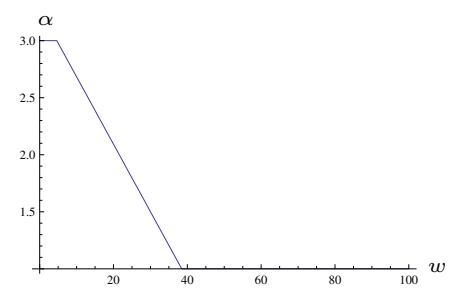

(a) Indifference line with price for study $p=10$

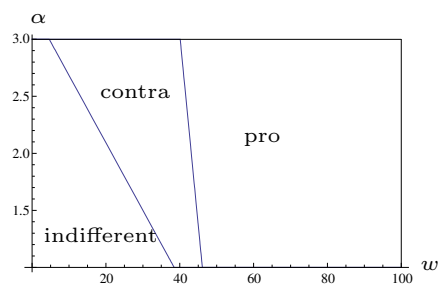

(b) Pro and contra for a price raise at $p=10$.

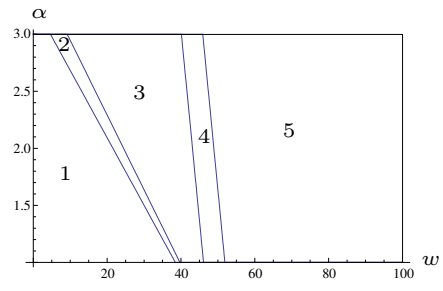

(c) Groups in society, raising the price from $p=10$ to $p=11$.

Figure 2.7: Indifference line to study (Figure 2.7(a) . Indifference line for a price change $\left(\frac{\partial V}{\partial p}\right)$ with resulting pro and contra groups for raising prices (Figure 2.7(b) . Groups in society, raising $p$ from 10 to 11 (Figure 2.7(c)).

If we set the price level for study to 10 , we can find the indifferent persons to study and to changing prices (Figure 2.7). In Figure 2.7(a) the indifference line for studying is shown. Moreover, Figure 2.7(b) shows the indifference line for a price change. This leads to three groups voting for at least an infinitesimally small change in price. If there is a plan to change the price from 10 to 11 , the already mentioned (see section 2.5 five groups will appear (Figure 2.7(c) .

In this example, at $p=10$ the group being in favor of raising prices to $p=11$ is quite large (group 5 in Figure 2.7(c) . Since group 1 is indifferent, there would be a good chance that the median voter is in favor of raising the price, but this is not clear. Although group 1 is indifferent, they are more likely to be against the raise in the hope of being able to lower the price some when later.

On the other hand, the higher the price, the smaller this group will be. Finally, when $p$ is high enough, only the smartest and richest upper right corner group will be in favor of raising the price.

\subsection{Conclusion}

In this chapter, a model is presented to explain a possible incentive for the richer and/or the more able subset of a society to raise tuition fees, even if there is no direct utility such 
as better study conditions or better equipment. The fundamental idea is a non-monetary utility influence through "social status" which increases if fewer people decide to study.

The model is kept as simple as possible. Hence, the quality effect of tuition is not considered to concentrate on the influence of the status effect. If one takes into account a possible uncertainty for the poor about future income and the fear of running into debt, the presented crowding out effect could be even stronger.

Another reason why the effect could be stronger than demonstrated is because even if utility of life would increase by attending university, some might refrain from enrolling due to uncertainty and incorrect assessment of opportunities in future.

Moreover, this chapter does not say anything about the political influence and the size of the group in favor of the tuition fees. This group will not likely be large enough to raise the tuition markedly, when thinking about a median voter situation. However, if there is no popular vote for the fees, the influence of the richer group in the form of representatives could be even higher.

Social planners must be aware that charging tuition fees will prevent some people from attaining universities, namely the poor and less able people. The social problem results when the poorer do not enroll solely due to a high utility value loss if they had paid the tuition fees. 


\title{
3 Honest Grading, Grade Inflation and Reputation
}

\author{
Authors: Tim Ehlers and Robert Schwager \\ Published in CESifo Economic Studies (2016) 62 (3): 506-521 \\ Online available http://dx. doi.org/10.1093/cesifo/ifv022
}

\begin{abstract}
When students receive better grades without any corresponding increase in ability, this is called grade inflation. Conventional wisdom says that such grade inflation is unavoidable since it is essentially costless to award good grades. In this article, we point out an effect driving into the opposite direction: Grade inflation is not actually costless, since it has an impact on future cohorts of graduates, or, put differently, by grading honestly, a school can build up reputation. Introducing a concern for reputation into an established signalling model of grading, we show that this mechanism reduces or even avoids grade inflation.
\end{abstract}




\section{Academic Achievement and Tracking - A Theory Based on Grading Standards}

Authors: Tim Ehlers and Robert Schwager

\subsection{Introduction}

A major controversy in education policy concerns whether students should be taught in comprehensive schools or whether classes should be tracked according to ability. For example, in Germany the results of the first PISA tests raised a debate about making the school system more comprehensive. Such a policy is motivated by the idea that mixing good and mediocre students improves the performance of mediocre students without harming the good students too much. This reasoning is largely supported by empirical research which often finds that tracking, or the ability composition of classes, affect the performance of individual students.

While such peer group effects seem to be well documented empirically, the mechanism driving them is rarely discussed. A possible explanation states that good students help mediocre colleagues to pass the exam and in addition learn by explaining the subject. Formally this can be modeled by a learning production function which depends on the average ability in class like in Arnott and Rowse (1987) and in Epple, Newlon and Romano (2002). While we do not question the relevance of this explanation, in this chapter we present a complementary theory which is based on the schools' grading policy. We show that the incentives created by grading standards alone can explain 
many empirical results on tracking without refering to any direct impact of classmates' ability on individual performance.

The idea of the peer goup effect goes back to the 1970's where this effect was first analyzed in the US. In this decade, for example Summers and Wolfe (1977) empirically analyzed the performance of students from the Philadelphia school district. They came to the conclusion that a high share of good students has a positive effect on the mediocre students, while the good students are not harmed. On the other hand the performance of both types is reduced if the share of mediocre students is too high. Summers and Wolfe conclude that in this case both mediocre and good students do not deploy their full potential.

Following up on this early contribution, a large literature has emerged which empirically analyzes peer group effects and the impact of tracking on educational outcomes. Surveys of this literature are provided by Meier and Schütz (2008) and Brunello and Checchi (2007). This research investigates the impact of tracking on average academic performance and on performance of students with different abilities. The latter question is linked to equality of opportunity, in the sense that academic achievement should not depend on the social background. This is especially relevant in the case of early tracking, since family background is likely to strongly influence the ability in the first years of schooling.

In this line of research Argys, Rees and Brewer (1996) find that the abolishment of tracking in the US would result in a large increase in performance of students in low ability classes, but on the other hand would decrease performance of students in high achieving classes. Similarly Woessmann (2010) concludes that less tracking leads to more equality of opportunity. In addition, Hanushek and Wößmann (2006) find a tendency that early tracking reduces average performance, but this cannot be found in all investigated countries. Waldinger (2006) also comes to the conclusion that early tracking of students with non-academic family background results in low academic achievement. He argues that the difference in achievement based on family background 
is already present before tracking takes place. Tracking does not reinforce this difference, but comprehensive schooling would reduce it.

Several contributions come to somewhat different conclusions, suggesting positive effects of tracking. Figlio and Page (2002) find no evidence that low ability students are harmed in a tracked environment, but that they may, in contrast, gain in a tracked class. The work by Kim, Lee and Lee (2008) uses data from South Korea, where tracking takes place in about half of the existing schools. Their main result states that tracking raises average achievement. It helps students above median ability and does not lower the achievement of students below it. Another study which does not yield negative effects of tracking is provided by Betts and Shkolnik (2000). According to their results, tracking does not significantly change achievement of low ability students. It has a small negative effect on students with moderate ability and a small positive effect on high ability students, which cancel out in average performance.

Summing up, the empirical literature agrees more or less that the family background plays a major role for academic achievement. This is reinforced by tracking, at least when tracking occurs early. Most studies also conclude that equality of opportunity is promoted by comprehensive schooling, in the sense that the achievement gap between students of different abilities or backgrounds is narrowed. In contrast, there does not seem to be clear evidence on whether average achievement rises or falls when students are tracked.

In this chapter we provide a simple model which can account for these facts. In the model there are two types of students distinguished by ability. These students are taught either in tracked classes or in a comprehensive school. The instrument of the school is the graduation standard, which is the level of performance required to pass the exam. In setting the standard, the school trades off wages of graduates, which rise in the standard, against effort costs required to meet a more demanding standard.

We consider two different dimensions of ability. The first dimension represents the endowment a student starts with. This endowment is the ability a student has when 
the tracking decision is taken. It results from previous learning, which is determined by family background and former schooling. Clearly, the earlier tracking occurs, the more relevant is the family background. We assume that students can reach an academic performance corresponding to the endowment without effort cost.

The second dimension of ability is the eagerness to learn or to improve personal achievement. This is the student's potential a teacher can work with. This dimension determines how hard is is for students to raise performance beyond their initial ability. Importantly, we do not exclude the case where students with low initial endowment have high eagerness to learn or vice versa.

We distinguish between the objective function of the student or teacher, and the objective the parents or society may have. While the latter only care for academic performance, the student incurs costs in terms of stress. We assume that the teacher takes these costs into account when setting the standard, implying that he or she chooses a standard below the standard preferred by society. This modeling is motivated by the emphasis which policy makers and researchers put on performance measuring tests like PISA and TIMMS, which disregard effort costs.

In this framework we characterize the standards chosen by tracked schools and by a comprehensive school, and compare the resulting academic achievements of both types of students. We show that it depends on the parameters whether students with lower initial endowment gain from a comprehensive school. In essence this occurs when their eagerness to learn is not too different from the eagerness of students with high initial endowment. In this case also the achievement gap between both types declines when classes are merged. This arises because in a comprehensive school the teacher is forced to set the standard as a compromise. This pushes lower ability students to higher achievement at the cost of stressing them excessively.

In a further result we compare average academic performance in the tracked and comprehensive school system. In line with the empirical literature, both systems may dominate in that respect. The average performance in the comprehensive system is 
higher if students with lower initial endowment have higher eagerness to learn. In this case the tracked system does not make full use of the learning potential of students with low initial endowment, on which tracking is based. In contrast, if students with low initial endowment also have lower eagerness to learn, average performance goes down when classes are merged.

It is worth noting that these results crucially depend on the two specific elements of our model. First, when all students have the same eagerness to learn and hence differ only in one dimension of ability, then a compromise standard at the comprehensive school necessarily leads to the same average performance as the separate standards of tracked schools. Second, in our model non-tracking will always be dominated by tracking if teachers and society share the same objective function. In the comprehensive school a unique standard must be chosen and one degree of freedom is given up. Therefore maximization of either average performance or welfare is carried out under an additional restriction in the comprehensive school, and a tracked school system is always preferable.

This chapter contributes to the theory of grading, initiated by Costrell (1994) and Betts (1998). We build upon the traditional model of Costrell, where students weigh the advantage of a degree against the disadvantage of exerting sufficient effort to pass the standard which is set by the teacher. Costrell (1997) puts his model into the context of central or decentralized standards. Since a centralized standard is uniform and decentralized standards are specific, this setting is similar to a comparison of untracked and tracked school systems. In addition Costrell's model, similarly to ours, allows for differences in abilities among schools. However, the focus of his analysis is different from ours. His main issue is that individual schools can free-ride on the tough standards of other schools in the case where employers can only observe the average achievement of graduates from all schools. In contrast we focus on tracking according to ability. Moreover, as stressed above, our model extends Costrell's setup by assuming two dimensions of ability and by replacing the ever positive marginal costs of learning by the idea that a certain performance level can be reached without costs. 


\subsection{The model}

There are two types of students $i \in\{l ; h\}$ which differ in ability. We consider two dimensions of ability. The first dimension, which we label endowment or initial ability, represents the level of performance a student can achieve without feeling stressed. We assume that students actually like to think, solve problems, and participate in class and that they feel bored if courses do not challenge them enough. Each individual of type $i$ has the same initial endowment $\gamma_{i=\{l ; h\}}$. We assume $\gamma_{l}<\gamma_{h}$, so that students of type $l$ have lower endowment than students of type $h$. To interpret the nature of differences in the initial endowment, we observe that the level of performance achievable without feeling stressed most likely depends on previous learning. Moreover, it is natural to think that $\gamma_{i}$ is largely determined by the upbringing and the parental background of students, as mentioned in the introduction.

The second dimension of ability, labeled $a_{i}$ for type $i$, expresses the ease of learning. This parameter measures how much stress a student feels if he or she pushes performance beyond his or her initial ability $\gamma_{i}$. We can interpret $a_{i}$ as the individual intellectual capacity and motivation of the student. Since a student with a low academic background can well be highly motivated or intelligent, we allow for the case $a_{l}>a_{h}$. This describes the situation where students of type $l$ have low initial endowment of ability but high eagerness and capacity to learn.

Depending on both dimensions of ability a student has costs $c_{i}$ to achieve a certain level of education, denoted by $e_{i}$ :

$$
c_{i}\left(e_{i}\right)=\frac{1}{2 a_{i}}\left(e_{i}-\gamma_{i}\right)^{2} .
$$

Here the inverse of $a_{i}$ enters the marginal cost of learning. There is a minimum at $e_{i}=\gamma_{i}$, where costs are zero. At this point the student's academic performance is just his or her initial ability. The cost function, shown in figure 4.1 represents the idea that demanding less effort leads to higher costs in terms of being bored. 


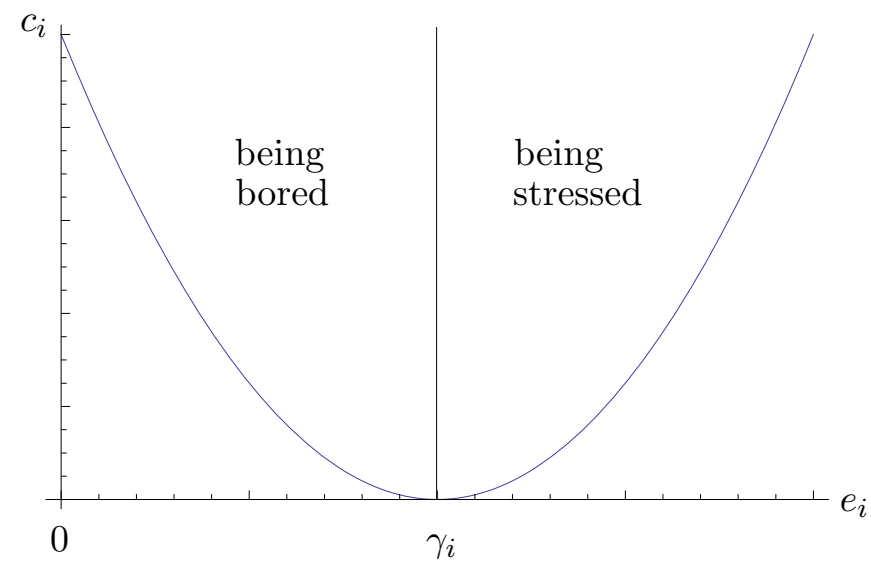

Figure 4.1: Cost as a function of effort for a student of type $i$. When effort equals initial ability $\gamma_{i}$, marginal cost of effort is zero.

We now turn to the examination and the labor market. We start in this section by analyzing the case where students are taught in classes tracked according to type. The school or the teacher set a standard $s_{i}$ which is measured in the same units as the level of education $e_{i}$. The level of personal education must be at least as high as the standard of the school in order to pass the final exam and graduate. The students decide to become graduates or not and, conditional on this, which academic performance to achieve. This decision is based on the cost of effort and the wages for non-graduates $w_{0 i}$ and graduates $w_{1 i}$. This formulation assumes that employers observe a student's type $i$ and whether he or she graduated or not. However, the individual performance $e_{i}$ is unknown to the employer and therefore does not enter the wage.

Conditional on the decision to pass the exam or not, the student chooses performance to maximize utility. We denote the utility achieved in case of passing (not passing) by $u_{1 i}\left(u_{0 i}\right)$ :

$$
\begin{array}{ll}
u_{1 i}=\max _{e_{i}}\left\{w_{1 i}-c_{i}\left(e_{i}\right) \mid e_{i} \geq s_{i}\right\} & \Rightarrow \begin{cases}e_{i}=s_{i} & \text { if } s_{i} \geq \gamma_{i} \\
e_{i}=\gamma_{i} & \text { if } s_{i}<\gamma_{i}\end{cases} \\
u_{0 i}=\max _{e_{i}}\left\{w_{0 i}-c_{i}\left(e_{i}\right)\right\} & \Rightarrow e_{i}=\gamma_{i} .
\end{array}
$$

Anticipating this choice, a student graduates if $u_{1 i} \geq u_{0 i}$. We assume that students 
expect $w_{1 i} \geq w_{0 i}$. One can see from equation (4.4) below that this expectation is confirmed in equilibrium. The graduation choice is then given by:

$$
\max \left\{u_{0 i} ; u_{1 i}\right\}= \begin{cases}u_{1 i} & \text { if } s_{i}<\gamma_{i} \\ u_{1 i} & \text { if } w_{1 i}-c_{i}\left(s_{i}\right)-w_{0 i} \geq 0 \quad \text { and } s_{i} \geq \gamma_{i} \\ u_{0 i} & \text { if } w_{1 i}-c_{i}\left(s_{i}\right)-w_{0 i}<0 \quad \text { and } s_{i} \geq \gamma_{i}\end{cases}
$$

In equilibrium, the wage after passing the exam $w_{1 i}$ must be equal to the expected productivity of graduates of class $i$. We normalize productivity to be measured in the same units as academic performance. Therefore $w_{1 i}$ equals the education level of graduates of class $i$. In the same way the wage $w_{0 i}$ is given by the academic performance of non-graduates. From equation 4.2 we have:

$$
\begin{array}{ll}
w_{0 i}=\gamma_{i} & \Rightarrow \text { no exam } \\
w_{1 i}=\max \left\{s_{i} ; \gamma_{i}\right\} & \Rightarrow \text { exam }
\end{array}
$$

We now turn to the choice of standard $s_{i}$ by the teacher. The teacher maximizes utility of all students. Thus, we assume that the teacher cares about the disutility of learning of his or her students. Inserting $(4.4)$ and $(4.1)$ into 4.3 shows that in the case where $s_{i} \geq \gamma_{i}$, the student chooses to graduate if $s_{i}-\gamma_{i} \leq 2 a_{i}$. Using this, 4.2 and (4.4) in (4.3) shows that utility of all students of type $i$ is given by:

$$
V_{i}\left(s_{i}\right)= \begin{cases}\gamma_{i} & \text { if } s_{i}<\gamma_{i} \text { or } s_{i}-\gamma_{i}>2 a_{i} \\ s_{i}-\frac{1}{2 a_{i}}\left(s_{i}-\gamma_{i}\right)^{2} & \text { if } s_{i} \geq \gamma_{i} \text { and } s_{i}-\gamma_{i} \leq 2 a_{i}\end{cases}
$$

The optimal standard $s_{i}^{*}$ is determined by:

$$
\frac{\partial V_{i}}{\partial s_{i}}=1-\frac{1}{a_{i}}\left(s_{i}-\gamma_{i}\right) \stackrel{!}{=} 0 \Rightarrow s_{i}^{*}=a_{i}+\gamma_{i} .
$$

The chosen standard reflects both dimensions of ability.

Comparing the two standards, the typical case is given by $s_{h}^{*}>s_{l}^{*}$, where $h$-students 
enjoy an advantage compared to $l$-students in terms of total ability:

$$
a_{h}+\gamma_{h}>a_{l}+\gamma_{l} .
$$

In this case one can clearly label both types of students as $l$-low and $h$-high ability. However we do not rule out the opposite case, where

$$
a_{h}+\gamma_{h} \leq a_{l}+\gamma_{l} .
$$

Thus, we allow the learning capacity of $l$-students to be so much higher than the one of $h$-students that it overcompensates the disadvantage of initial endowment of the $l$-students.

\subsection{Merging classes}

The previous analysis dealt with separated classes $i \in\{l ; h\}$. In contrast in this section we consider the case where both classes can be mixed together in one comprehensive school. We denote the share of $h$-students in the comprehensive school by $0<d<1$. The teacher sets a common standard $s$ applying to all students in the mixed class. The teacher's objective function is the aggregate utility of all students, denoted by $V(s)$. We continue to assume that employers are able to observe the standard of the school and the type of an applicant $i$. Therefore, for any given standard $s$, individual choices of students are still determined by $(4.2)$ and $(4.3)$ and wages are still given by (4.4), where $s_{i}$ is replaced by $s$.

Depending on the standard, one of four constellations can occur. First, all students choose a performance equal to their initial ability $\gamma_{i}$. We denote the value of the school's

objective function in this case by $\tilde{V}_{0}$. Since in this case every student of type $i$ earns a wage equal to $\gamma_{i}$ and has no cost, it follows $\tilde{V}_{0}=\gamma_{l}(1-d)+\gamma_{h} d$. This constellation will not occur in equilibrium. 
Second, only for the $l$-students the standard is binding, while the $h$-students choose performance $\gamma_{h}$. Using the wage (4.4) and the cost function (4.1), aggregate utility in this case is $\tilde{V}_{l}(s)=\left[s-\frac{1}{2 a_{l}}\left(s-\gamma_{l}\right)^{2}\right](1-d)+\gamma_{h} d$.

Third, both types of students choose to graduate and have to incur effort costs to do so. Then performance of students of both types just meets the standard $s$. Hence, the school's objective is $\tilde{V}(s)=\left[s-\frac{1}{2 a_{l}}\left(s-\gamma_{l}\right)^{2}\right](1-d)+\left[s-\frac{1}{2 a_{h}}\left(s-\gamma_{h}\right)^{2}\right] d$.

Fourth, $l$-students perform at their initial ability $\gamma_{l}$, while $h$-students meet the standard. This yields the objective function $\tilde{V}_{h}(s)=\gamma_{l}(1-d)+\left[s-\frac{1}{2 a_{h}}\left(s-\gamma_{h}\right)^{2}\right] d$.

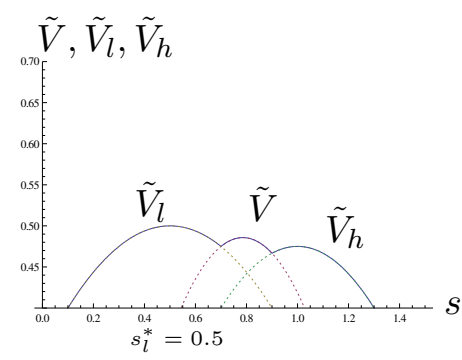

(a) Parameter: $d=0.5$, $\gamma_{h}=0.7, \gamma_{l}=0.1$, $a_{h}=0.3, a_{l}=0.4$

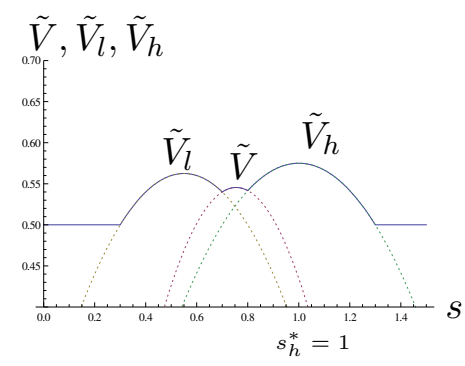

(b) Parameter: $d=0.5$, $\gamma_{h}=0.7, \gamma_{l}=0.3$ $a_{h}=0.3, a_{l}=0.25$

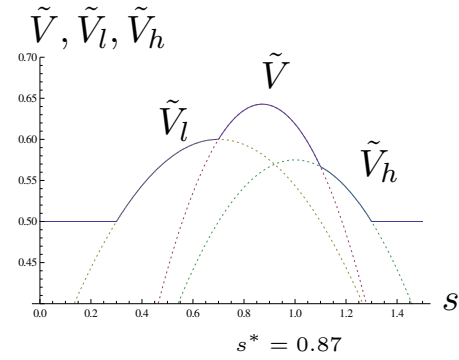

(c) Parameter: $d=0.5$, $\gamma_{h}=0.7, \gamma_{l}=0.3$, $a_{h}=0.3, a_{l}=0.4$

Figure 4.2: The objective function of the comprehensive school $V(s) . \tilde{V}_{h}\left(\tilde{V}_{l}\right)$ describes the value of the schools objective, if one assumes that $h(l)$-students exert effort to pass the exam and $l(h)$-students choose the effort level $\gamma_{l}\left(\gamma_{h}\right) . V$ is the upper envelope of $\tilde{V}, \tilde{V}_{l}$ and $\tilde{V}_{h}$.

Which one of these four cases applies depends on the parameter constellation. This leads to the following definition of $V(s)$ with seven branches defined by parameter restrictions. Some of the restrictions are redundant, but are left for better understanding: 


$$
V(s)= \begin{cases}\tilde{V}_{0} & {[1] \quad \text { if } s \leq \gamma_{l, h}} \\ \tilde{V}_{0} & {[2] \quad \text { if } s \leq \gamma_{h} ; s>\gamma_{l} ; s-\gamma_{l}>2 a_{l}} \\ \tilde{V}_{l}(s) & {[3] \quad \text { if } s \leq \gamma_{h} ; s>\gamma_{l} ; s-\gamma_{l} \leq 2 a_{l}} \\ \tilde{V}(s) & {[4] \quad \text { if } s>\gamma_{l, h} ; s-\gamma_{l} \leq 2 a_{l} ; s-\gamma_{h} \leq 2 a_{h}} \\ \tilde{V}_{h}(s) & {[5] \quad \text { if } s>\gamma_{l, h} ; s-\gamma_{l}>2 a_{l} ; s-\gamma_{h} \leq 2 a_{h}} \\ \tilde{V}_{l}(s) & {[6] \quad \text { if } s>\gamma_{l, h} ; s-\gamma_{l} \leq 2 a_{l} ; s-\gamma_{h}>2 a_{h}} \\ \tilde{V}_{0} & {[7] \quad \text { if } s>\gamma_{l, h} ; s-\gamma_{l}>2 a_{l} ; s-\gamma_{h}>2 a_{h}}\end{cases}
$$

In the first branch [1] the standard is too low to bind anybody, so all students just perform at the initial endowment. In the next branch [2] outcome is the same, but the standard is above the maximal standard the $l$-students are willing to satisfy and $u_{1 l}<u_{0 l} . \quad h$-students still graduate without effort cost. Branch [3] represents the situation where the $l$-students graduate by just meeting the standard whereas $h$-students still graduate with level $\gamma_{h}$. On branch [4], the standard is high enough to be binding also for $h$-students. Branches [5] and [6] differ depending on which group first refuses to satisfy the high standard and falls back to initial ability. In branch [5] this is true for the $l$-students and in branch [6] for the $h$-students. The last branch [7] shows a standard higher than anybody will accept to meet.

Notice that the branches [3]-[6] of the expression $V(s)$ are strictly concave. Moreover, observe that $\tilde{V}_{l}$ and $\tilde{V}_{h}$ are affine transformations of the objective functions $V_{l}$ and $V_{h}$ of the separated classes: $\tilde{V}_{l}(s)=(1-d) V_{l}(s)+d \gamma_{h}$ and $\tilde{V}_{h}(s)=d V_{h}(s)+(1-d) \gamma_{l}$. Consequently in the branches [3], [5], and [6], where one of these functions applies, the optimal standard is $s_{l}^{*}$ or $s_{h}^{*}$. In branch [4], the optimal standard $s^{*}$ solves:

$$
\frac{\partial \tilde{V}}{\partial s}=\left[1-\frac{1}{a_{l}}\left(s-\gamma_{l}\right)\right](1-d)+\left[1-\frac{1}{a_{h}}\left(s-\gamma_{h}\right)\right] d \stackrel{!}{=} 0 .
$$


From this first order condition of $\tilde{V}$, we obtain:

$$
\begin{aligned}
s^{*} & =\frac{a_{l} a_{h}+d a_{l} a_{h}+\gamma_{h} \gamma_{l}-d a_{h} \gamma_{l}}{a_{h}(1-d)+a_{l} d} \\
& =\frac{d a_{l}}{a_{h}(1-d)+a_{l} d} s_{h}^{*}+\frac{(1-d) a_{h}}{a_{h}(1-d)+a_{l} d} s_{l}^{*} .
\end{aligned}
$$

The standard of a mixed class is a weighted average of the standards chosen in separated classes. The weights combine the population shares $d$ and $(1-d)$ with the ability parameters $a_{h}$ and $a_{l}$.

Figure 4.2 shows the different branches of $V$. The sub-figures $4.2(\mathrm{a}), 4.2(\mathrm{~b})$ and $4.2(\mathrm{c})$ are based on different parameter combinations, where the optimal standard is $s_{l}^{*}, s_{h}^{*}$ and $s^{*}$ respectively. We will now analyze in which branch of $V$ the optimal standard is located, that is, which of these three standards gives the highest welfare. Pairwise comparison of the local maxima obtained by the three standards shows that

$$
\begin{aligned}
& \tilde{V}\left(s^{*}\right) \gtreqless \tilde{V}_{l}\left(s_{l}^{*}\right) \quad \Leftrightarrow \quad F_{l}\left(a_{l}, a_{h}, \gamma_{l}, \gamma_{h}, d\right) \gtreqless 0 \\
& \tilde{V}\left(s^{*}\right) \gtreqless \tilde{V}_{h}\left(s_{h}^{*}\right) \quad \Leftrightarrow \quad F_{h}\left(a_{l}, a_{h}, \gamma_{l}, \gamma_{h}, d\right) \lesseqgtr 0 \\
& \tilde{V}_{h}\left(s_{h}^{*}\right) \gtreqless \tilde{V}_{l}\left(s_{l}^{*}\right) \quad \Leftrightarrow \quad F_{l h}\left(a_{l}, a_{h}, d\right) \lesseqgtr 0,
\end{aligned}
$$

where

$$
\begin{aligned}
F_{l}\left(a_{l}, a_{h}, \gamma_{l}, \gamma_{h}, d\right) & =a_{h}\left[a_{l}(2-d)-2(1-d)\left(\gamma_{h}-\gamma_{l}\right)\right]-(1-d)\left(a_{l}-\gamma_{h}+\gamma_{l}\right)^{2} \\
F_{h}\left(a_{l}, a_{h}, \gamma_{l}, \gamma_{h}, d\right) & =a_{h}^{2} d+d\left(\gamma_{h}-\gamma_{l}\right)\left(\gamma_{h}-\gamma_{l}-2 a_{l}\right)-a_{h}\left(a_{l}+a_{l} d-2 d \gamma_{h}+2 d \gamma_{l}\right) \\
F_{l h}\left(a_{l}, a_{h}, d\right) & =a_{l}(1-d)-a_{h} d .
\end{aligned}
$$

These functions define boundaries between subsets of the parameter space. Depending on the signs of the three functions $F_{l}, F_{h}$ and $F_{l h}$, there could be up to eight such subsets. Two of these do not exist, however, since the three functions cannot be all positive or all negative at the same time. For example, if $F_{h}>0$ and $F_{l}>0$, then equations 4.10 imply $\tilde{V}_{h}\left(s_{h}^{*}\right)>\tilde{V}\left(s^{*}\right)>\tilde{V}_{l}\left(s_{l}^{*}\right)$, hence $F_{l h}<0$. 
Proposition 4.1 In the comprehensive school the chosen standard is:

$$
\begin{array}{rlrl}
s^{*} & =\frac{d a_{l}}{a_{h}(1-d)+a_{l} d} s_{h}^{*}+\frac{(1-d) a_{h}}{a_{h}(1-d)+a_{l} d} s_{l}^{*} & & \text { if } F_{l}>0 \text { and } F_{h}<0 \\
s_{l}^{*}=a_{l}+\gamma_{l} & \text { if } F_{l}<0 \text { and } F_{l h}>0 \\
s_{h}^{*}=a_{h}+\gamma_{h} & \text { if } F_{h}>0 \text { and } F_{l h}<0 .
\end{array}
$$

\section{Proof.}

We need to consider all three possible optimalities and check if the needed constrains from 4.8 are satisfied.

At first we consider $s^{*}$ is optimal.

We need to show that if $F_{l}>0$ and $F_{h}<0$ hold, $s^{*}$ satisfies the conditions given in branch [4] of 4.8.

$s^{*}>\gamma_{l}$ is equivalent to $a_{l}\left[a_{h}(1-d)+a_{l} d\right]\left[a_{h}+d\left(\gamma_{h}-\gamma_{l}\right)\right]>0$, which is satisfied in any case.

$s^{*}>\gamma_{h}$ is equivalent to $a_{h}\left[a_{h}(1-d)+a_{l} d\right]\left[\left(\gamma_{h}-\gamma_{l}\right)(1-d)-a_{l}\right]<0$, which reduces to $a_{l}>\left(\gamma_{h}-\gamma_{l}\right)(1-d)$. The inequality $F_{l}>0$ is equivalent to $a_{h}\left[a_{l}(2-d)-2(1-d)\left(\gamma_{h}-\gamma_{l}\right)\right]>$ $(1-d)\left(a_{l}-\gamma_{h}+\gamma_{l}\right)^{2}$. This implies $a_{l}(2-d)-2(1-d)\left(\gamma_{h}-\gamma_{l}\right)>0$, which can be transformed into $a_{l}-(1-d)\left(\gamma_{h}-\gamma_{l}\right)>\frac{a_{l} d}{2}$. From this $a_{l}>(1-d)\left(\gamma_{h}-\gamma_{l}\right)$ and hence $s^{*}>\gamma_{h}$ follows.

$s^{*}-\gamma_{l} \leq 2 a_{l}$ is, for $a_{l} \neq 0$, equivalent to $a_{l} \geq \frac{d\left(\gamma_{h}-\gamma_{l}\right)+a_{h}(2 d-1)}{2 d} \equiv A_{l}\left(a_{h}\right) . F_{h}<0$ is equivalent to $a_{l}>\frac{d\left(a_{h}+\gamma_{h}-\gamma_{l}\right)^{2}}{a_{h}(1+d)+2 d\left(\gamma_{h}-\gamma_{l}\right)} \equiv B_{l}\left(a_{h}\right)$. We show that $B_{l}\left(a_{h}\right) \geq A_{l}\left(a_{h}\right)$ so that $a_{l}>B_{l}\left(a_{h}\right)$ implies $a_{l}>A_{l}\left(a_{h}\right)$. To see this, observe that $B_{l}\left(a_{h}\right) \geq A_{l}\left(a_{h}\right)$ is equivalent to $-a_{h}(1-d) d\left[a_{h}+d\left(\gamma_{h}-\gamma_{l}\right)\right]\left[a_{h}+a_{h} d+2 d\left(\gamma_{h}-\gamma_{l}\right)\right] \leq 0$, which is true in any case.

$s^{*}-\gamma_{h} \leq 2 a_{h}$ is, for $a_{h} \neq 0$, equivalent to $a_{h} \geq \frac{a_{l}(1-2 d)-(1-d)\left(\gamma_{h}-\gamma_{l}\right)}{2(1-d)} \equiv A_{h}\left(a_{l}\right)$. $F_{l}>0$ implies that $a_{l}(2-d)-2(1-d)\left(\gamma_{h}-\gamma_{l}\right)>0$. Hence $F_{l}>0$ is equivalent to $a_{h}>\frac{(1-d)\left(a_{l}-\gamma_{h}+\gamma_{l}\right)^{2}}{a_{l}(2-d)-2(1-d)\left(\gamma_{h}-\gamma_{l}\right)} \equiv B_{h}\left(a_{l}\right)$. We show that $B_{h}\left(a_{l}\right) \geq A_{h}\left(a_{l}\right)$ so that $a_{h}>$ $B_{h}\left(a_{l}\right)$ implies $a_{h}>A_{h}\left(a_{l}\right)$. The inequality $B_{h}\left(a_{l}\right) \geq A_{h}\left(a_{l}\right)$ is equivalent to $a_{l}(1-$ 
d)d $d\left[a_{l}(2-d)-2(1-d)\left(\gamma_{h}-\gamma_{l}\right)\right]\left[a_{l}-(1-d)\left(\gamma_{h}-\gamma_{l}\right)\right]>0$. As shown in the proof of $s^{*}>\gamma_{h}$, we have $a_{l}(2-d)-2(1-d)\left(\gamma_{h}-\gamma_{l}\right)>0$ and $a_{l}-(1-d)\left(\gamma_{h}-\gamma_{l}\right)>0$. Hence $B_{h}\left(a_{l}\right)>A_{h}\left(a_{l}\right)$ for all $a_{l}>0$.

\section{$s_{l}^{*}$ is optimal.}

Now we need to show that if $F_{l}<0$ and $F_{l h}>0$ hold, $s_{l}^{*}$ satisfies the conditions given in branch [3] or [6] of 4.8. We distinguish two cases, depending on whether 4.6) or 4.7 holds. In the first case, where $a_{h}+\gamma_{h}>a_{l}+\gamma_{l}$, we show that branch [3] of 4.8 applies. In this case $F_{l}<0$ is equivalent to $a_{l}<\frac{a_{h}(2-d)+2(1-d)\left(\gamma_{h}-\gamma_{l}\right)-\sqrt{a_{h}} \sqrt{a_{h}(2-d)^{2}+4(1-d) d\left(\gamma_{h}-\gamma_{l}\right)}}{2(1-d)} \equiv$ $C_{l}\left(a_{h}\right)$. Observe that $C_{l}\left(a_{h}\right)<\gamma_{h}-\gamma_{l}$ is equivalent to $4(1-d) d\left(\gamma_{h}-\gamma_{l}\right)>0$, which is true. Hence we have $a_{l}<C_{l}\left(a_{h}\right)<\gamma_{h}-\gamma_{l}$, which proves $s_{l}^{*} \leq \gamma_{h}$. The conditions $s_{l}^{*}>\gamma_{l}$ and $s_{l}^{*}-\gamma_{l} \leq 2 a_{l}$ follow from $s_{l}^{*}=a_{l}+\gamma_{l}$.

In the case $a_{h}+\gamma_{h} \leq a_{l}+\gamma_{l}$ the branch [6] of (4.8) applies. The first two conditions $s_{l}^{*}>\gamma_{l}$ and $s_{l}^{*} \leq 2 a_{l}+\gamma_{l}$ follow directly from $s_{l}^{*}=a_{l}+\gamma_{l}$. We show that the condition $s_{l}^{*}-\gamma_{h}>2 a_{h}$ follows from $F_{l}<0$. Inserting $s_{l}^{*}=a_{l}+\gamma_{l}$, we can rewrite this condition as $a_{h}<\frac{a_{l}+\gamma_{l}-\gamma_{h}}{2} \equiv C_{h}\left(a_{l}\right)$. Consider the denominator of $B_{h}\left(a_{l}\right)$ defined above. From $a_{h}-a_{l}<\gamma_{l}-\gamma_{h}$ we have $a_{l}(2-d)-2(1-d)\left(\gamma_{h}-\gamma_{l}\right)>a_{l}(2-d)+2(1-d)\left(a_{h}-a_{l}\right)=$ $a_{l} d+2(1-d) a_{h}>0$. Therefore $F_{l}<0$ is equivalent to $a_{h}<B_{h}\left(a_{l}\right)$. We show that $B_{h}\left(a_{l}\right)<C_{h}\left(a_{l}\right)$, so that $a_{h}<B_{h}\left(a_{l}\right)$ implies $a_{h}<C_{h}\left(a_{l}\right)$. The inequality $B_{h}\left(a_{l}\right)<C_{h}\left(a_{l}\right)$ is equivalent to $\left[a_{l}(-2+d)+2(1-d)\left(\gamma_{h}-\gamma_{l}\right)\right]\left(a_{l}+\gamma_{l}-\gamma_{h}\right)<0$. Since here $a_{l}+\gamma_{l}-\gamma_{h}>a_{h}>0$, this is equivalent to $a_{l}(2-d)-2(1-d)\left(\gamma_{h}-\gamma_{l}\right)>0$, which we just have shown to be true.

\section{$s_{h}^{*}$ is optimal.}

$F_{h}>0$ is equivalent to $a_{l}<B_{l}\left(a_{h}\right)$, where $B_{l}\left(a_{h}\right)$ is defined above. $s_{h}^{*}-\gamma_{l}>2 a_{l}$ is equivalent to $a_{l}<\frac{a_{h}+\gamma_{h}-\gamma_{l}}{2} \equiv D_{l}\left(a_{h}\right)$. We show that $B_{l}\left(a_{h}\right)<D_{l}\left(a_{h}\right)$. Knowing $a_{h}+a_{h} d+2 d\left(\gamma_{h}-\gamma_{l}\right)>0$ and $d<1$, this is true. Hence $a_{l}<B_{l}\left(a_{h}\right)$ implies $a_{l}<D_{l}\left(a_{h}\right)$. The conditions $s_{h}^{*}>\gamma_{h}$ and $s_{h}^{*}-\gamma_{h} \leq 2 a_{h}$ follow from $s_{h}^{*}=a_{h}+\gamma_{h}$.

From this proposition we can directly read the globally optimal standard. This is $s^{*}$ if the parameters are such that $F_{l}>0$ and $F_{h}<0$. If one of these inequalities is not 
satisfied, the optimal standard is $s_{l}^{*}$ or $s_{h}^{*}$, depending on the sign of $F_{l h}$.

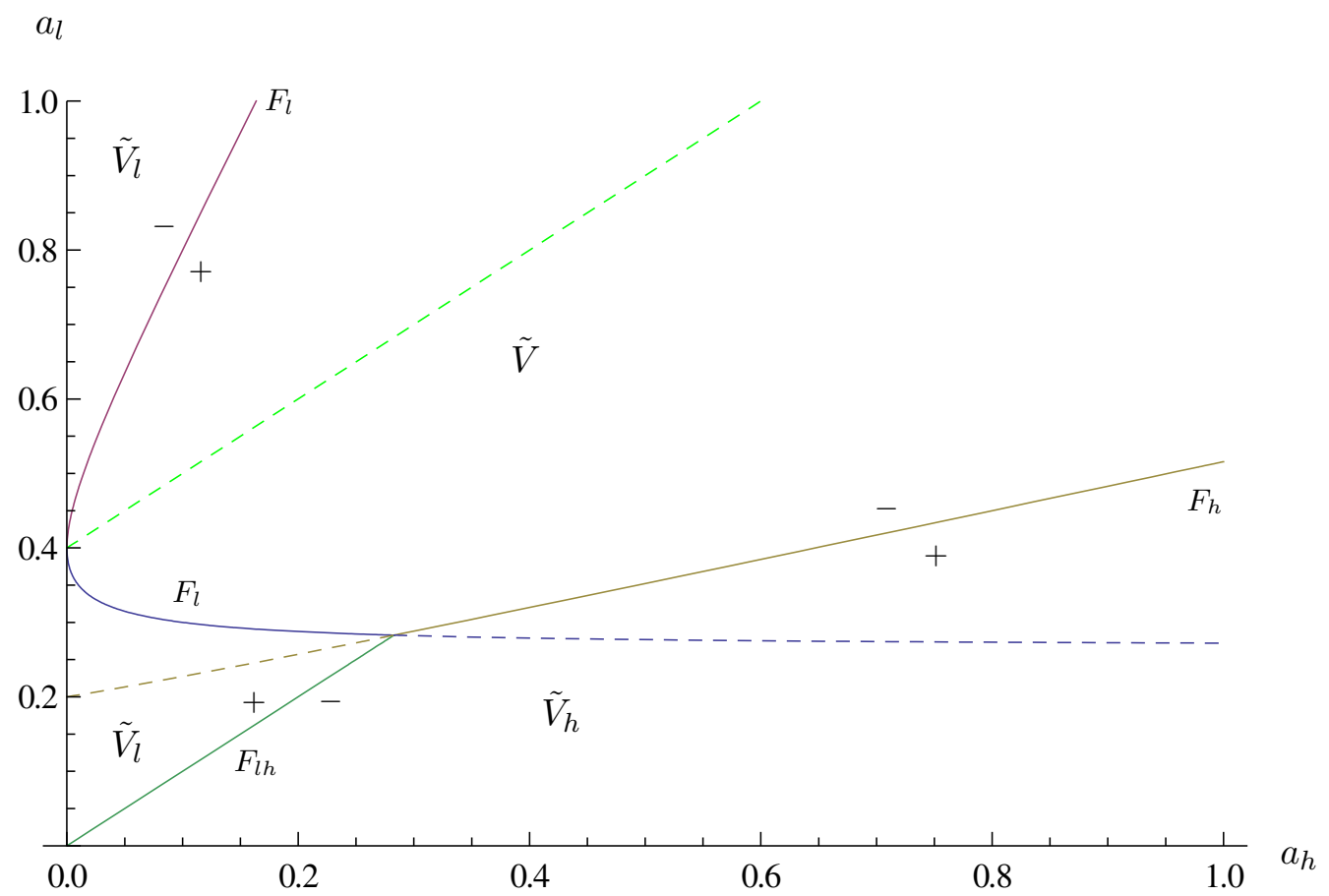

Figure 4.3: Parameter regions in $a_{h}-a_{l}$-space with different optimal standards in the comprehensive school, with $d=0.5, \gamma_{l}=0.3$ and $\gamma_{h}=0.7$. The labels $\tilde{V}, \tilde{V}_{l}$ and $\tilde{V}_{h}$ show in which branch of $V$ the global maximum is located. Below (on, above) the dotted line starting at $\left(a_{h}=0 ; a_{l}=0.4\right)$ one has $a_{l}+\gamma_{l}<(=,>) a_{h}+\gamma_{h}$.

Figure 4.3 illustrates in which region of the parameter space each of the three local maxima is the global maximum. This figure is drawn in $a_{h}-a_{l}$-space, since the influence of these parameters on the optimal standard is most interesting to study. In this example the other parameters were fixed at $d=0.5, \gamma_{l}=0.3$ and $\gamma_{h}=0.7$. In the graph we inserted a dotted straight line, starting at $a_{h}=0 ; a_{l}=0.4$. Above this line inequality (4.7) holds. Below this line we have (4.6), such that labeling the $l$-type as low ability students is appropriate.

In the lower right region of the figure, labeled with $\tilde{V}_{h}$, the relevant branch of $V$ in equation (4.8) is [5]. In this region the ability of $h$-students is relatively high in both dimensions compared to the $l$-students. Therefore the teacher sets a standard tailored exactly to $h$-students, accepting that $l$-students will drop out. In the central and upper 
right region, labeled $\tilde{V}$, branch [4] of $V$ contains the optimum. Abilities of both types do not differ much and hence the teacher sets the compromise standard $s^{*}$. Finally in the upper left and lower left regions, labeled with $\tilde{V}_{l}$, the school chooses the standard $s_{l}^{*}$ for the $l$-students, whereas the $h$-students perform at $\gamma_{h}$. They do so for two different reasons. In the upper region with $a_{l}>0.4$, where branch [6] of $V$ is relevant and 4.7) holds, the standard is too high for the $h$-students and they drop out. In the lower part $\left(a_{l}<0.4\right.$, branch [3], and (4.6) holds), the standard is so low that the $h$-students can meet it without effort cost.

The next proposition provides comparative statics for the case where the optimal standard is $s^{*}$.

Proposition 4.2 If the optimal standard in a comprehensive school is $s^{*}$, it increases in $a_{l}, a_{h}, \gamma_{l}$ and $\gamma_{h}$. It increases (decreases) in $d$ if $a_{h}+\gamma_{h}>(<) a_{l}+\gamma_{l}$.

\section{Proof.}

Differentiating $s^{*}$ from 4.9 we obtain:

$$
\begin{aligned}
\frac{\partial s^{*}}{\partial d} & =\frac{a_{h} a_{l}\left(a_{h}-a_{l}+\gamma_{h}-\gamma_{l}\right)}{\left(a_{h}(1-d)+a_{l} d\right)^{2}} \\
\frac{\partial s^{*}}{\partial \gamma_{l}} & =\frac{a_{h}(1-d)}{a_{h}(1-d)+a_{l} d}>0 \\
\frac{\partial s^{*}}{\partial \gamma_{h}} & =\frac{a_{l} d}{a_{h}(1-d)+a_{l} d}>0 \\
\frac{\partial s^{*}}{\partial a_{l}} & =\frac{a_{h}(1-d)\left[a_{h}+d\left(\gamma_{h}-\gamma_{l}\right)\right]}{\left[a_{h}(1-d)+a_{l} d\right]^{2}}>0 \\
\frac{\partial s^{*}}{\partial a_{h}} & =\frac{a_{l} d\left[a_{l}-\left(\gamma_{h}-\gamma_{l}\right)(1-d)\right]}{\left[a_{h}(1-d)+a_{l} d\right]^{2}} .
\end{aligned}
$$

(4.12) is positive (negative) if $a_{h}+\gamma_{h}>(<) a_{l}+\gamma_{l}$. 4.13) is positive if $a_{l}>\left(\gamma_{h}-\gamma_{l}\right)(1-d)$. As shown in the proof of Proposition 4.1, this is true if $s^{*}>\gamma_{h}$, which must be the case if $s^{*}$ is the optimal choice.

As expected, for all students the standard increases in both dimensions of ability. Moreover, the standard increases in the share of the type of students $i$ whose total 
ability, measured by $a_{i}+\gamma_{i}$, is larger.

We now turn to the question whether two separated classes are preferable to the mixed class. It is important to distinguish between a comparison of utilities and a comparison of academic performances. Regarding utilities, no case is possible where students are better off in the mixed class than in separated classes, because in that case, $s_{l}^{*}$ and $s_{h}^{*}$ can be optimized separately. Hence, comparison of utilities is a straightforward application of the decentralization theorem by Oates (1972). Notice that the same observation would hold if we assumed that schools maximize academic performance or wages instead of students' utility. In such a model it would be immediate that in the comprehensive school performance of each type can only be worse than in tracked schools.

In contrast, as we will now show, in our model academic performance can also increase by mixing the classes. First, we consider for each type of students separately how their performance changes if classes are merged. For this comparison, observe that in the case where the optimal standard of the comprehensive school is $s_{l}^{*}\left(s_{h}^{*}\right)$, the performance of the $h(l)$-students is $\gamma_{h}\left(\gamma_{l}\right)$, and that the standard $s^{*}$ is a weighted average of the standards chosen in the tracked schools. With this, Proposition 4.1 immediately leads to:

Proposition 4.3 If the comprehensive school chooses $s_{l}^{*}\left(s_{h}^{*}\right)$, the performance of $h(l)$ students is lower than in the tracked $h(l)$-school. If the comprehensive school chooses $s^{*}$, the performance of l-students is higher than (lower than, equal to) the performance in the tracked l-school if $a_{l}+\gamma_{l}<(>,=) a_{h}+\gamma_{h}$. If the comprehensive school chooses $s^{*}$, the performance of h-students is higher than (lower than, equal to) the performance in the tracked $h$-school if $a_{l}+\gamma_{l}>(<,=) a_{h}+\gamma_{h}$.

This proposition shows that our model can generate a positive peer group effect for low ability students, by which we mean the $l$-students, where 4.6$)$ holds. In a comprehensive school, teachers will need to find a compromise between the standards tailored to individual student types. As long as low ability students are still willing to meet this standard, they will put in more effort than in the separated class. As 
a consequence one will observe higher test results on their part in the comprehensive school, even if there are no synergy effects from teaching diverse students together. Furthermore, the reduction of the standard for the $h$-students might be quite small when $d$ and/or $a_{l}$ are relatively large. Then, as (4.9) shows, the standard of the mixed class is close to the standard of the $h$-class. Given confounding influences, an empirical study might fail to find statistical significance of such a small impact.

The peer group effect obtains only for a subset of the parameter space. As is apparent from figure 4.3 the learning capacities of both types must not be too different. Otherwise, if one type finds it substantially easier to learn, the school will set optimal incentives for this type and put up with the fact that the other type stops graduating. Furthermore one can show that the $F_{h}=0$ curve shifts downwards if $d$ decreases. Hence, a positive peer group effect for the low ability students is more likely when these students are more numerous. In this case the teacher of the comprehensive school puts more weight on their utility and therefore refrains from setting a standard which overburdens them.

Finally it may also happen that the comprehensive school sets the standard $s_{l}^{*}$ tailored to the low ability students. This corresponds to the lower left region of Figure 4.3 . In this case mixing classes leaves the performance of $l$-students unchanged and reduces the performance of $h$-students. However, this decline in performance might be very small, since learning capacity of $h$-students is anyway not very large and since they continue to perform at their initial endowment $\gamma_{h}$. Therefore, although mixing classes obviously does not help in this case, the damage it inflicts is small.

The next proposition deals with the effect of merging classes on aggregate performance.

Proposition 4.4 If $a_{l}+\gamma_{l}<a_{h}+\gamma_{h}$, the average productivity of students in a comprehensive school exceeds (is equal to, falls short of) the average productivity of students in tracked schools if and only if learning ability of l-students is larger than (is equal to, is 
smaller than) learning ability of h-students. That is:

$$
s^{*} \gtreqless d s_{h}^{*}+(1-d) s_{l}^{*} \Leftrightarrow a_{l} \gtreqless a_{h} .
$$

If $a_{l}+\gamma_{l}>(=) a_{h}+\gamma_{h}$, the average productivity of students in a comprehensive school falls short of (is equal to) the average productivity of students in tracked schools.

Proof. From equation 4 4.9, we find that $s^{*} \gtreqless d s_{h}^{*}+(1-d) s_{l}^{*}$ is equivalent to:

$$
\left(a_{l}-a_{h}\right)\left(s_{h}^{*}-s_{l}^{*}\right) \gtreqless 0 .
$$

In the case $a_{l}+\gamma_{l}<a_{h}+\gamma_{h}$ we have $s_{h}^{*}>s_{l}^{*}$, and 4.14 is equivalent to $a_{l} \gtreqless a_{h}$. In the case $a_{l}+\gamma_{l}>a_{h}+\gamma_{h}$ we have $s_{h}^{*}<s_{l}^{*}$, and 4.14 is equivalent to $a_{l} \lesseqgtr a_{h}$. Since $\gamma_{h}>\gamma_{l}$, in this case $a_{l}>a_{h}$ must hold. Hence $s^{*}<d s_{h}^{*}+(1-d) s_{l}^{*}$. For $a_{l}+\gamma_{l}=a_{h}+\gamma_{h}$, we have $s_{l}^{*}=s_{h}^{*}$, and (4.14) implies $s^{*}=d s_{h}^{*}+(1-d) s_{l}^{*}$.

This proposition shows that merging classes with heterogeneous students may increase overall academic performance, even when there are no spillover effects between types of students. This occurs when students with low initial ability have higher learning capacity than students with high initial ability. To understand that, consider how the standard is set in the comprehensive school. The teacher will trade off the net-loss incurred by $l$-students when the standard is increased above their optimal standard $s_{l}^{*}$ against the net-loss incurred by $h$-students when the standard is decreased below $s_{h}^{*}$. Since the learning ability of $l$-students exceeds the learning ability of $h$-students, the net-loss of the latter increases faster than the net-loss of the former. Therefore the optimal standard, where marginal net-losses are equalized, is closer to $s_{h}^{*}$ than to $s_{l}^{*}$. Hence the optimal standard in the mixed class is higher than the weighted average of the standards of the separated classes.

This kind of result is likely to be relevant in education systems where students are tracked early. It is likely that the allocation to different tracks is mostly determined by the endowment of skills conferred by the family background. At the same time it is well 
possible that students with low endowment have not yet fully unfolded their potential and correspondingly find it easier to extend their knowledge. In the terminology of our model these students have high learning capacity $a_{l}$, but low endowment $\gamma_{l}$. If these students now attend a comprehensive school, average performance of students will increase. Both types of students find a relatively high standard acceptable, but they do so because of different reasons: One group starts with high initial ability and the others are eager to advance.

\subsection{Conclusion}

In this chapter we present a model comparing the choice of examination standards by tracked and untracked schools. The model distinguishes between initial ability and the capacity or willingness to extend ability. When setting the standard, the school or teacher takes the student's disutility of learning into account. Therefore, the resulting choices differ from the standards which maximizes academic performance, which is the focus of PISA and similar studies.

Our findings show that in many cases a comprehensive school will enhance performance of low ability students or even enhance average performance compared to tracked schools with individual standards. In these cases performance of high ability students decreases, but this effect may be so small that it is insignificant in an empirical study. Our model therefore provides a foundation of peer group effects although we abstract from any synergy effect from teaching different student types together. 


\section{Concluding Remarks}

This thesis analyzes different questions in the field of education, using the method of theoretical modeling. In chapter $2 \mathrm{I}$ add a second dimension to the classic utility function in terms of a non-monetary value, the social status. In a second step social status explains incentives for possibly influential circles to vote for tuition fees without direct gain from it. In chapter 3 it is shown that findings in a one shot signaling game, resulting in grade inflation, can mostly be traced back to the character of the one shot game. Extending the game in the time dimension to have at least a second round where the university enjoys the reputation set, grade inflation is decreased, in some parameter constellations even abolished. Finally, in chapter 4 it is shown that empirical findings which suggest that in heterogeneous classes the average productivity is higher than the average in tracked classes, could be an effect of overburdening the low performing students, who will still meet the high standard for the price of most of their childhood/free time. this means, politics, society and parents need to balance between a happy-go-lucky childhood and preparing their children for working life. 


\section{Bibliography}

Argys, Laura M, Daniel I Rees, and Dominic J Brewer, "Detracking America's Schools: Equity at Zero Cost?," Journal of Policy Analysis and Management, 1996, $15(4), 623-645$.

Arnott, Richard and John Rowse, "Peer Group Effects and Educational Attainment," Journal of Public Economics, 1987, 32 (3), 287-305.

Becker, Gary S., "Human Capital: A Theoretical and Empirical Analysis, with Special Reference to Education," University of Illinois at Urbana-Champaign's Academy for Entrepreneurial Leadership Historical Research Reference in Entrepreneurship, 1964 .

, Human Capital: A Theoretical and Empirical Analysis, with Special Reference to Education NBER Books, second ed., National Bureau of Economic Research, Inc, February 1975.

, Human Capital: A Theoretical and Empirical Analysis, with Special Reference to Education, third ed., University of Chicago Press, 1993.

Betts, Julian R, "The Impact of Educational Standards on the Level and Distribution of Earnings," American Economic Review, 1998, 88 (1), 266-75.

__ and Jamie L Shkolnik, "The Effects of Ability Grouping on Student Achievement and Resource Allocation in Secondary Schools," Economics of Education Review, 2000, 19 (1), 1-15.

Brunello, Giorgio and Daniele Checchi, "Does School Tracking Affect Equality of Opportunity? New International Evidence," Economic Policy, 2007, 22 (52), $782-861$.

Campbell, Robert and Barry N. Siegel, "THE DEMAND FOR HIGHER EDUCATION IN THE UNITED STATES, 1919-1964.," American Economic Review, $1967,57(3), 482$.

Chan, William, Li Hao, and Wing Suen, "A Signaling Theory of Grade Inflation," International Economic Review, 2007, 48 (3), 1065-1090.

Cohn, Elchanan and Terry G Geske, The Economics of Education, Pergamon, 1990.

Connelly, Brian L, S Trevis Certo, R Duane Ireland, and Christopher $\mathbf{R}$ Reutzel, "Signaling Theory: A Review and Assessment," Journal of Management, 2011, 37 (1), 39-67. 
Costrell, Robert M., "A Simple Model of Educational Standards," The American Economic Review, September 1994, 84 (4), 956-971.

, "Can Centralized Educational Standards Raise Welfare?," Journal of Public Economics, 1997, 65, 271-293.

Denison, Edward, Trends in American Economic Growth, Brookings Institution Press, 2011.

Ehlers, Tim, "University Graduation Dependent on Family's Wealth, Ability and Social Status," Center for European, Governance and Economic Development (CEGE) Research, 2011, 120.

_ _ and Robert Schwager, "Academic Achievement and Tracking-A Theory Based on Grading Standards," Center for European, Governance and Economic Development (CEGE) Research, 2016, 289.

and __ , "Honest Grading, Grade Inflation, and Reputation," CESifo Economic Studies, 2016, 62 (3), 506-521.

Epple, Dennis, Elizabeth Newlon, and Richard Romano, "Ability Tracking, School Competition, and the Distribution of Educational Benefits," Journal of Public Economics, 2002, 83 (1), 1-48.

Ermisch, John and Marco Francesconi, "Family Matters: Impacts of Family Background on Educational Attainments," Economica, 2001, 68 (270), 137-156.

Figlio, David N and Marianne E Page, "School Choice and the Distributional Effects of Ability Tracking: Does Separation Increase Inequality?," Journal of Urban Economics, 2002, 51 (3), 497-514.

Frankfurter Allgemeine Zeitung, "Studienkosten und -finanzierung im internationalen Vergleich," Website 2005. Available online at http://www.faz.net/ -00pr56 visited on December 9th 2010.

, "Zahltag im britischen Hörsaal," Website 2010. Available online at http://www faz.net/-0119ii; visited on December 9th 2010.

Gary-Bobo, Robert J. and Alain Trannoy, "Efficient Tuition Fees and Examinations," Journal of the European Economic Association, 2008, 6 (6), pp. 1211-1243.

Hanushek, Eric A. and Ludger Wößmann, "Does Educational Tracking Affect Performance and Inequality? Differences- in-Differences Evidence Across Countries," The Economic Journal, 2006, 116 (510), C63-C76.

Hanushek, Eric A, Ludger Woessmann, Eliot A Jamison, and Dean T Jamison, "Education and Economic Growth," Education Next, 2008, 8 (2).

Heckman, James J., "A Life-Cycle Model of Earnings, Learning, and Consumption," The Journal of Political Economy, 1976, 84 (4), pp. 11-44. 
Hetmeier, Heinz-Werner, Arne Schmidt, Silvia Vogel, and Nicole Buschle, Bildungsfinanzbericht 2015, Wiesbaden: Statistisches Bundesamt, 2015.

Huebner, Malte, "Do tuition fees affect enrollment behavior? Evidence from a 'natural experiment' in Germany," Economics of Education Review, 2012, 31 (6), 949-960.

Kemnitz, Alexander, "Educational Federalism and the Quality Effects of Tuition Fees," CESifo Working Paper Series, 2010.

Kim, Taejong, Ju-Ho Lee, and Young Lee, "Mixing versus Sorting in Schooling: Evidence from the Equalization Policy in South Korea," Economics of Education Review, 2008, 27 (6), 697-711.

Kirmani, Amna and Akshay R Rao, "No Pain, no Gain: A Critical Review of the Literature on Signaling Unobservable Product Quality," Journal of marketing, 2000, $64(2), 66-79$.

Levhari, David and Yoram Weiss, "The Effect of Risk on the Investment in Human Capital," The American Economic Review, 1974, 64 (6), 950-963.

Meier, Volker and Gabriela Schütz, "The Economics of Tracking and non-Tracking," Zeitschrift für Betriebswirtschaft, 2008, Special Issue 1, 23-43.

Mincer, Jacob, Schooling, Experience, and Earnings, National Bureau of Economic Research, Inc, 1974.

Oates, Wallace E, Fiscal Federalism, New York: Harcourt Brace Jovanovich, 1972.

Parsons, Donald O, "The Cost of School Time, Foregone Earnings, and Human Capital Formation," Journal of Political Economy, 1974, 82 (2), 251-266.

Rey, Elena Del, "Can State University Fees Increase Welfare? A Mixed Oligopoly Approach," Journal of Institutional and Theoretical Economics (JITE), December 2009, 165 (4), pp. 670-683.

Rivkin, Steven G, Eric A Hanushek, and John F Kain, "Teachers, Schools, and Academic Achievement," Econometrica, 2005, 73 (2), 417-458.

Ross, Stephen A, "The Determination of Financial Structure: The Incentive-Signalling Approach," The bell journal of economics, 1977, pp. 23-40.

Schultz, Theodore W., "Investment in Human Capital," The American Economic Review, 1961, 51 (1), pp. 1-17.

, The economic value of education, Vol. 63, Columbia University Press New York, 1963.

, Investing in People: The Economics of Population Quality, Univ of California Press, 1982. 
Schwager, Robert, "Public Universities, Tuition and Competition: A Tiebout Model," Zeitschrift fuer Betriebswirtschaft/Journal of Business Economics, 2008, Sonderheft 1/2008, pp. 71-89.

Spence, Michael, "Job Market Signaling," The quarterly journal of Economics, 1973, 87 (3), 355-374.

Summers, Anita A. and Barbara L. Wolfe, "Do Schools Make a Difference?," The American Economic Review, 1977, 67 (4), 639-652.

Swanson, Austin D and Richard Adams King, School Finance: Its Economics and Politics, Longman Publishing Group, 1991.

Waldinger, Fabian, "Does Tracking Affect the Importance of Family Background on Students' Test Scores?," Unpublished manuscript, LSE, 2006.

Weiss, Andrew, "Human Capital vs. Signalling Explanations of Wages," The Journal of Economic Perspectives, 1995, 9 (4), 133-154.

Woessmann, Ludger, "Institutional Determinants of School Efficiency and Equity: German States as a Microcosm for OECD Countries," Jahrbücher für Nationalökonomie und Statistik, 2010, 230 (2), 234-270. 